\title{
Decoupling social status and status certainty effects on health in macaques: a network approach
}

\author{
Jessica J Vandeleest ${ }^{\text {Corresp., }}{ }^{1,2}$ ， Brianne A Beisner ${ }^{1,2}$ ， Darcy L Hannibal ${ }^{1,2}$, Amy C Nathman ${ }^{2}$, John P Capitanio ${ }^{2}$ \\ , Fushing Hsieh ${ }^{3}$, Edward R Atwill ${ }^{1}$, Brenda McCowan ${ }^{1,2}$ \\ 1 Population Health \& Reproduction, University of California, Davis, Davis, California, United States \\ 2 Brain, Mind and Behavior, California National Primate Research Center, Davis, California, United States \\ 3 Department of Statistics, University of California, Davis, Davis, California, United States \\ Corresponding Author: Jessica J Vandeleest \\ Email address: vandelee@ucdavis.edu
}

Background. Although a wealth of literature points to the importance of social factors on health, a detailed understanding of the complex interplay between social and biological systems is lacking. Social status is one aspect of social life that is made up of multiple structural (humans: income, education; animals: mating system, dominance rank) and relational components (perceived social status, dominance interactions). In a nonhuman primate model we use novel network techniques to decouple two components of social status, dominance rank (a commonly used measure of social status in animal models) and dominance certainty (the relative certainty vs. ambiguity of an individual's status), allowing for a more complex examination of how social status impacts health. Methods. Behavioral observations were conducted on three outdoor captive groups of rhesus macaques ( $\mathrm{N}=252$ subjects). Subjects' general physical health (diarrhea) was assessed twice weekly, and blood was drawn once to assess biomarkers of inflammation (interleukin-6, tumor necrosis factor-alpha, and C-reactive protein). Results. Dominance rank alone did not fully account for the complex way that social status exerted its effect on health. Instead, dominance certainty modified the impact of rank on biomarkers of inflammation. Specifically, high-ranked animals with more ambiguous status relationships had higher levels of inflammation than low-ranked animals, whereas little effect of rank was seen for animals with more certain status relationships. The impact of status on physical health was more straightforward: individuals with more ambiguous status relationships had more frequent diarrhea; there was marginal evidence that high-ranked animals had less frequent diarrhea. Discussion. Social status has a complex and multifaceted impact on individual health. Our work suggests an important role of uncertainty in one's social status in status-health research. This work also suggests that in order to fully explore the mechanisms for how social life influences health, more complex metrics of social systems and their dynamics are needed. 
1 Full Title: Decoupling Social Status and Status Certainty Effects on Health in Macaques: A

2

3

4

5

6 Jessica J. Vandeleest ${ }^{1,2, \uparrow, *}$, Brianne A. Beisner ${ }^{1,2, \pi}$, Darcy L. Hannibal ${ }^{1,2}$, Amy C. Nathman ${ }^{1}$, John

7 P. Capitanio ${ }^{1}$, Hsieh Fushing 3 , Edward R. Atwill ${ }^{2}$, Brenda McCowan ${ }^{1,2}$.

$8{ }^{1}$ Brain, Mind and Behavior, California National Primate Research Center, Davis, CA, 95616

9 USA

${ }^{2}$ Population Health \& Reproduction, University of California, Davis, Davis, CA, 95616 USA

11

${ }^{3}$ Department of Statistics, University of California Davis, Davis, CA 95616 USA

12

13

*Corresponding author:

14

E-mail: vandelee@ucdavis.edu (JV)

15

16

I JV and BB are Co-first authors

\section{Network Approach}

Short Title: Status Certainty and Health 


\section{Abstract}

Background. Although a wealth of literature points to the importance of social factors on health, a detailed understanding of the complex interplay between social and biological systems is lacking. Social status is one aspect of social life that is made up of multiple structural (humans: income, education; animals: mating system, dominance rank) and relational components (perceived social status, dominance interactions). In a nonhuman primate model we use novel network techniques to decouple two components of social status, dominance rank (a commonly used measure of social status in animal models) and dominance certainty (the relative certainty vs. ambiguity of an individual's status), allowing for a more complex examination of how social status impacts health.

Methods. Behavioral observations were conducted on three outdoor captive groups of rhesus macaques ( $\mathrm{N}=252$ subjects). Subjects' general physical health (diarrhea) was assessed twice weekly, and blood was drawn once to assess biomarkers of inflammation (interleukin-6, tumor necrosis factor-alpha, and C-reactive protein).

Results. Dominance rank alone did not fully account for the complex way that social status exerted its effect on health. Instead, dominance certainty modified the impact of rank on biomarkers of inflammation. Specifically, high-ranked animals with more ambiguous status relationships had higher levels of inflammation than low-ranked animals, whereas little effect of rank was seen for animals with more certain status relationships. The impact of status on physical health was more straightforward: individuals with more ambiguous status relationships had more frequent diarrhea; there was marginal evidence that high-ranked animals had less frequent diarrhea. 
42 Discussion. Social status has a complex and multi-faceted impact on individual health. Our work

43 suggests an important role of uncertainty in one's social status in status-health research. This

44 work also suggests that in order to fully explore the mechanisms for how social life influences

45 health, more complex metrics of social systems and their dynamics are needed.

46

47 


\section{Introduction}

Social life influences mental and physical health (Thoits, 2011; Nunn et al., 2015). For example, a lack of satisfactory social relationships has been shown to be associated with poor health and high quality relationships can buffer individuals from stress (Hostinar et al., 2014; Hawkley and Capitanio, 2015). Treatment and prevention of illness thus requires a detailed understanding of the complex interplay between social and biological systems. Although past research has clearly shown that the social environment plays a critical role in shaping health, the effect of the complex and multi-scale dynamic nature of social relationships on health remains poorly understood (Thoits, 2011). For example, although the absence of social relationships has been associated with poor health outcomes, social life consists of more than just the presence or absence of social relationships. Qualities of these relationships, such as stability and role within the community, are also important factors (Sapolsky, 1992; Thoits, 2011). Therefore, approaches that empirically recognize the inherent complexity of social life are critical to improve our understanding of how social life influences health. In this paper, we use a nonhuman primate model to investigate an understudied aspect of social status and its effects on health outcomes. We use a measure of status certainty to test whether greater uncertainty in status relationships is coincident with greater levels of inflammation and poor health outcomes.

Status is one component of social life whose impact on health has been widely studied. While in humans there is a clear general pattern that individuals of low status (i.e. socioeconomic status) often have greater disease incidence and shorter lifespans (Adler et al., 1994; Marmot and Sapolsky, 2014; Chetty et al., 2016), across species the impact of status on health is less clear (Creel, 2001; Habig and Archie, 2015). For example, in species such as baboons, macaques, marmots, and meerkats, low status individuals are at greater risk of poor health outcomes, such 
71 as poor cardiovascular health, reduced immune function, and higher levels of glucocorticoids

72 (GCs) (Sapolsky and Mott, 1987; Sapolsky and Share, 1994; Shively and Clarkson, 1994;

73

74

75

76

77

78

79

80

81

82

83

84

85

86

87

88

89

90

91

92 93

Hackländer et al., 2003; Young et al., 2006; Archie et al., 2012). While GCs are not a health outcome, they are frequently used as a biomarker for increased risk for negative health outcomes because they are released in response to social stress and play an important role in regulating immune function (Sapolsky et al., 2000). In contrast, the potential costs of high status center on GCs and parasite loads. In social carnivores and many cooperative breeding species, high status individuals tend to have higher GCs than low status individuals (summarized in: Creel, 2001; Creel et al., 2013). In addition, high status individuals across a variety of species have been shown to experience higher parasite loads than low status individuals (Habig and Archie, 2015). Compounding this confusion are species in which status effects differ by sex or study population (Schoech et al., 1991; Creel et al., 1996; Arnold and Dittami, 1997) as well as species in which no status effects on health have been found (Mays et al., 1991; Wingfield et al., 1991; Lynch et al., 2002). Recently, researchers have attempted to reconcile these differences to examine broad associations between social status and health across species. For example, a recent meta-analysis examining the impact of status on immune parameters and parasite load found little evidence for consistent effects of status on immune function but did find that high status males are at greater risk for parasitic infections (Habig and Archie, 2015).

The lack of cross species consensus on the impact of social status on health may be partly due to the fact that social status is more complex than a simple linear ranking of individuals based upon income, education level, or, in the case of nonhumans, dominance. The advancement of novel network techniques provides an opportunity to begin measuring the complexity of social life in new ways. Social networks have been shown to impact both mental and physical health 
94 outcomes, highlighting the utility of these methods in understanding population health (Pachucki 95 et al., 2015; Perkins et al., 2015). One understudied, and potentially critical, aspect of status is

96 the relative stability and predictability associated with one's status. In the human literature,

97 unpredictability in access to resources (e.g. food, medical care, housing) and job insecurity have

98 been suggested to be features of low socioeconomic status that contribute to poorer health

99 outcomes (Adler et al., 1994). In the animal literature, group-level instability of the hierarchy and

100 dominance rank reversals have similarly been suggested to influence patterns of association

101 between social status and health (e.g. Sapolsky, 1992; Muller and Wrangham, 2004; Sapolsky,

102 2005). Even within a stable social group, individual-level social relationships are dynamic and

103 can vary in stability (Hinde, 1976). For example, while a change in rank may be stressful for

104 both individuals involved, the negative impact on health is often greater for the animal that loses

105 rank compared to the animal that gains rank (e.g. Sapolsky, 1992; Shively and Clarkson, 1994).

106 This body of work highlights that the impact of status on health may depend not only on one's

107 position in the hierarchy, but also on the stability and predictability of one's status relationships.

108 Therefore, we propose that a measure of social status that quantifies such individual-level

109 instability or uncertainty may explain cross-species differences regarding the impact of status on

110 health outcomes.

111 We use a nonhuman primate model to disentangle two components of status, dominance

112 rank (linearly ordered status relative to other animals in the group) and dominance certainty (the

113 probability that status is decided and stable), using a novel computational network-based

114 approach called Percolation and Conductance (Fushing et al., 2011a; Fujii et al., 2014). This

115 method characterizes the flow of status (i.e. the overall direction of aggression and submission)

116 through pathways in the network and each individual's fit within that hierarchical flow to 
117 quantify both dominance rank and dominance certainty. Like most methods for measuring

118 dominance rank, Percolation and Conductance uses direct aggression and/or submission data to

119 create a dominance hierarchy. Unlike other methods, however, it uses information from indirect

120 pathways through the network of aggressive interactions to modify the likely rank association

121 between individuals and to measure the consistency of information flow through the network

122 (Fushing et al., 2011a). For example, if animal A directs aggression at animal E (and E submits)

123 and E directs aggression at D (and D submits), we can infer that A likely outranks D even if they

124 have never been observed to interact (see Figure 1A). Greater consistency in the direction of

125 dominance pathways from A to D results in higher certainty that A outranks D (Figure 1A),

126 whereas evidence of inconsistent direction (e.g. between F and I in Figure 1B) reflects

127 dominance ambiguity. Our method thus solves the problem of sparse or missing data in the

128 win/loss matrix (e.g. the treatment of zeroes in the matrix is a non-trivial issue: (de Vries, 1995))

129 by using these dominance pathways as additional sources of information about each pairwise

130 dominance relationship. Our method additionally provides a measure of how well the direction

131 of each individual's dominance interactions fit, on average, within the larger group-level pattern

132 of aggression from dominants to subordinates, a measure we call dominance certainty.

133 Our study aimed to examine the relative impacts of dominance rank and dominance

134 certainty on biomarkers of inflammation and diarrhea, with particular interest in whether

135 individual level dominance certainty either better explains variation in health or moderates the

136 rank-health association. Similar to results reported in baboons and long-tailed macaques

137 (Sapolsky and Share, 1994; Shively and Clarkson, 1994), we expected to find that low-ranked

138 individuals exhibited poorer health than high-ranked individuals. We predicted, however, that

139 reduced certainty in dominance relationships may be associated with poorer health outcomes 
140 either independent of rank or specifically among individuals that stand to lose rank, inasmuch as

141 uncertainty in one's relationships is likely to be stressful. We chose to include both biomarkers

142 of immune function as well as a general health outcome because previous research suggests that

143 effects of status are not always the same across health measures (Habig and Archie, 2015).

\section{Materials \& Methods}

Subjects and Housing. The subjects of this study were 252 rhesus macaques (71 males,

147 enclosures containing multiple A-frame structures, suspended barrels, swings, and perches and were free to interact as they chose. Animals were fed a standard diet of monkey chow twice per day at approximately $0700 \mathrm{~h}$ and between 1430 and $1530 \mathrm{~h}$. Fresh fruit or vegetables were provided one time per week and seed mixture provided daily. Water was available ad libitum. Animals housed in outdoor enclosures were managed with a minimum level of disturbance. At the end of the study all subjects were relinquished to the CNPRC breeding colony. This research was approved by the University of California Davis Institutional Animal Care and Use Committee.

Rank and Dominance Certainty Data Collection. Each group was observed for 5-7 weeks, one group in spring (Group A: March-April 2013) and two in fall (Group B: SeptemberOctober 2013, Group C: September-October 2014) as part of a larger study on social networks and health. Unexpected management events resulted in lengthening (e.g. Group A) or shortening (e.g. Group B) the 6-week study period by a few days in certain groups. We used an event 
163 sampling design to collect all instances of aggressive and submissive interactions. Two observers 164 collected data for 6 hours on 4 days per week from 0900-1200 h and 1300-1600 h. Aggressive 165 and submissive events were recorded as a series of dyadic interactions. A total of 13,567 events 166 were recorded during 444 hours of observation. Aggression was categorized according to 167 severity and included threat (open mouth stare, brow flash, ear flap), mild aggression (threat and 168 follow, lunge, push, slap, chase $<6$ meters), moderate aggression (grapple, wrestle, chase $>6$ 169 meters), and intense aggression (pin or bite). Submission categories included freeze/turn away, 170 move away, run away $<6$ meters, run away $>6$ meters, and crouch. Data on all dyadic 171 aggressive interactions were used for constructing aggression networks to calculate dominance 172 rank and certainty.

173 Dominance rank and certainty were calculated using the Perc package in R (Fujii et al., 174 2015) which uses a new network-based approach that combines information from direct 175 dominance interactions with information from multiple indirect dominance pathways (via 176 common third parties) to quantify dyadic dominance relationships (Fushing et al., 2011b; Fujii et 177 al., 2015). Essentially, individuals with dominance pathways that run counter to the primary 178 direction of aggression (or submission) in the hierarchy have more ambiguous status than 179 individuals who do not. The method begins by using a modified random walk algorithm to 180 exhaustively identify all directed pathways in the network (e.g., $\mathrm{A} \rightarrow \mathrm{B} \leftarrow \mathrm{C}$ is not a directed 181 pathway, but $\mathrm{A} \rightarrow \mathrm{B} \rightarrow \mathrm{C}$ is). To determine how much to weight the imputed (i.e. indirect) 'wins' 182 from these pathways, the transitivity of the network is calculated as the proportion of transitive 183 triangles (as opposed to cyclic or nontransitive triangles). In networks with high transitivity such 184 as ours ( $>95 \%$ of triangles are transitive, such that $A>B>C$ and $A>C$ ), a 'win' that is imputed 185 from an indirect pathway is more likely to reflect the true direction of dominance, and thus given 
186 higher weight, than in a network with lower transitivity. Regardless, wins from direct

187 interactions are always weighted more than imputed 'wins' from network pathways. Finally,

188 given the number of direct wins and imputed 'wins' from pathways, we calculate the probability

189 that the row animal is dominant to the column animal using a Beta distribution to incorporate a

190 source of statistical probability that reflects the level of uncertainty expected given the current

191 data on each pair (for a more detailed explanation, see: Fushing et al., 2011a). The matrix of

192 these dyadic dominance probability values (range: $0-1$ ) thus represent the cumulative

193 information from all network pathways between each pair of animals. A dyadic dominance

194 probability of 1 reflects the highest possible certainty that the row animal outranks the column

195 animal, whereas 0.5 means the dominance relationship is perfectly ambiguous. The matrix of

196 dyadic dominance probabilities was then used to generate the lowest cost linear rank order (see

197 Fushing et al., 2011b for details).

198 Sparse and missing data (i.e. pairs of animals that are either infrequently or never

199 observed to interact) are a common problem in animal behavior, and most ranking methods (such

200 as the IS\&I method (de Vries, 1998), Elo-rating (Neumann et al., 2011; Viswanath, 2016) and

201 the Bradley-Terry model: (Boyd and Silk, 1983; Albers and de Vries, 2001) are vulnerable to

202 sparse data. The Percolation and Conductance method addresses the problem of sparse and

203 missing data by gathering dominance information from network pathways. For example, in our

204 study group A only $42.3 \%$ of all possible dyads had at least one agonistic interaction in the

205 network. The remaining dyads were never observed to interact, making estimation of their

206 pairwise dominance relationships from direct interactions prone to error. Furthermore, of the

$20742.3 \%$ that did interact, they averaged less than 2 interactions per dyad $(\mathrm{x}=1.89)$. Adding

208 dominance pathways dramatically increased the information per dyad to an average of 207.4 
209 dominance pathways across all pairs (using up to 3 -step pathways: $A \rightarrow B \rightarrow C \rightarrow D$ ). Given that

210 transitivity is very high, the dominance information from pathways has a high probability of

211 agreeing with the true relationship. Furthermore, it is likely that macaques have the cognitive

212 capacity to use this dominance information because many social vertebrates are capable of

213 transitive inference such as deducing $\mathrm{A}>\mathrm{C}$ from $\mathrm{A}>\mathrm{B}$ and $\mathrm{B}>\mathrm{C}$ (McGonigle and Chalmers, 1977;

214 Davis, 1992; Bond et al., 2003; Grosenick et al., 2007).

215 From these dyadic dominance probabilities (which contain both rank direction and

216 certainty information), an average dominance probability was calculated for each subject to

217 provide a metric of the overall certainty of each animal's rank. Prior to averaging, we

218

219

220

221

222

223

224

225

226

227

228

229

230

231

transformed the dyadic dominance probabilities (initially bounded by $0-1$ ) to range between 0.5 (ambiguous) and 1.0 (certain), thereby focusing on the information about certainty and ignoring rank direction. We also transformed ordinal dominance ranks for each group (derived from permuting the rows and columns of the dominance probability matrix) into the proportion of animals outranked within their respective groups (i.e. 0 is the lowest ranked animal and 1 is the highest ranked animal) to account for differences in group size. For the purposes of graphical representation, individual-level average dominance certainty was categorized into high, moderate, and low certainty categories for each group. We examined empirical distributions of average dominance certainty values (performed on each group separately) using the segmented package in R to identify logical break-points for these categories (Muggeo, 2008). Groups differed in their break-points due to differences in distribution, and these group-specific categorizations of low vs. moderate vs. high dominance certainty are thus reflected in our plots. Social Network Measures and Independence. Statistical analysis of social network metrics requires some attention to the lack of independence in network data. The calculation of a 
232 network metric for one node (e.g., an individual) typically involves some of the same edges as

233 the same calculation for other nodes (Croft et al., 2008). As a result, a change in the value of one

234 node could potentially affect the values of other nodes. We experimentally verified that this lack

235 of independence was not an issue in this study by recalculating network measures after removing

236 single individuals from the network. We selected three individuals with differing betweenness

237 centrality (i.e. highest, median, and lowest) and experimentally removed each individual from

238 the aggression network, one-at-a-time, recalculating the values of the remaining individuals each

239 time, for a total of 3 recalculations ( 1 for each individual). We chose to examine betweenness

240 centrality because it is defined by shortest paths between all pairs in the network, similar to the

241 counting of all paths between pairs in our Percolation and Conductance method. Bivariate and

242 Spearman rank order correlations between the original dominance certainty and the new values

243 indicate very little change (bivariate pairwise correlations for (a), (b) and (c): $0.999 \geq \mathrm{r} \geq 0.932$;

244 Spearman pairwise correlations: $0.998 \geq \mathrm{r} \geq 0.941$ ). Furthermore, our Percolation and

245 Conductance method incorporates statistical probability/uncertainty into the calculation of each

246 dyadic dominance probability value, which serves to dampen any effect of dependence in the

247 data.

248

Blood Sample Collection. Blood samples were collected on a single day (between 0800 -

$2491200 \mathrm{~h}$ ) during the fifth week of the 5-7 week observation period for each group using the

250 CNPRC's standard method for biannual physical examinations. On sampling days, all animals in

251 the group were immobilized (10 mg/kg of ketamine) and given standard physical examinations

252 by veterinary staff (e.g., checked for injuries, weighed, assessed for pregnancy). Blood samples

253 (5 mL) were also obtained from the femoral vein and serum was aliquoted and stored at $-80{ }^{\circ} \mathrm{C}$

254 for later assay. Due to the large number of animals, blood was collected in batches of $\sim 15$ 
255 samples. Batches were labeled with collection start and end times and animal identity to track the

256 order of sample processing and control for effects of the capture and sedation procedure for

257 animals processed later in the morning.

258 General Health Assessments. Health indicators were recorded twice weekly by one

259 observer between 0900-1200 h and 1300-1600 h. The observer located and visually inspected

260 each study subject in the group and scored presence/absence of liquid stool (i.e. observing

261 defecation of liquid stool or observing fresh liquid fecal matter on the tail or rump). From these

262 data, we counted the total frequency of bouts of diarrhea per subject across the 5-7 week

263 observation period. A bout of diarrhea was defined as either a single observation day with liquid

264 stool or multiple consecutive observation days with liquid stool with the end of a bout marked by

265 at least one observation day with no evidence of liquid stool. Occasionally animals were

266 temporarily removed from the cage for veterinary care and were not available for health

267 observations - these absences were recorded to control for total observation days.

268 Pro-inflammatory Proteins. We measured three pro-inflammatory proteins (interleukin-6

269 (IL-6), tumor necrosis factor-alpha (TNF- $\alpha$ ), and C-reactive protein (CRP)) from frozen serum.

270 These proteins were chosen because they are markers of general systemic inflammation and are

271 demonstrated risk factors for multiple diseases (e.g. type 2 diabetes and atherosclerosis, Pradhan

272 et al., 2001; Libby et al., 2002).

273 Cytokine Assay. Serum levels of IL-6 and TNF- $\alpha$ were measured using commercially

274 available, species specific Milliplex multi-analyte profiling (MAP) reagents purchased from

275 EMD / Millipore (Billerica, MA), and utilizing Luminex Xmap technology (Luminex, Austin,

276 TX). Color coded polystyrene microbeads coated with specific antibodies for IL-6 and TNF- $\alpha$

277 were incubated with the serum samples, washed, and then were further reacted with biotinylated 
278 detector antibodies followed by Streptavidin-PE to label the immune complexes on the beads.

279 After a final washing to remove all unbound material, the beads were interrogated in a BioPlex

280 dual laser (BioRad, Hercules, CA). The median fluorescent index for each sample was compared

281 to a standard curve to calculate the concentration. Samples were tested in duplicate and had an

282 intra-assay coefficient of variability of $15.3 \%$. Samples falling below the threshold sensitivity of

283 the assay $(1.6 \mathrm{pg} / \mathrm{mL})$ were assigned a value of one.

284 C-Reactive Protein Assay. Concentrations of CRP were determined using a latex particle

285 immunoturbidmetric method on the Beckman Coulter AU480 clinical chemistry analyzer.

286 Data analysis. Data analysis proceeded through a two-step process. First, hypothesized

287 models (see below and Table 1) were tested for 4 dependent variables including three pro-

288 inflammatory proteins (CRP, TNF- $\alpha$, and IL-6) and one general health outcome (frequency of

289 diarrhea bouts). The sets of hypotheses that guided model-fitting were explored for the following

290 reasons. Age and sex were included as main effects in all models because both have been

291 previously found to influence health (Klein, 2000; Sansoni et al., 2008). The impact of rank on

292 health is also known to vary by sex in some populations (Creel et al., 1996; Abbott et al., 2003),

293 and it is reasonable to expect that the impact of rank may manifest differently at different ages.

294 Therefore, sex by rank and age by rank interaction terms were also explored. We also examined

295 a sex by dominance certainty interaction because the inherent structural differences in male vs.

296 female rank acquisition (i.e. individual-level features such as age and body size drive male rank:

297 (Dittus, 1975; Sprague, 1992; Sprague, 1998; Sebastian, 2015); family-level features such as

298 agonistic support drive female rank: (Sade, 1972; Datta, 1986)) suggest that ambiguity may arise

299 more readily amongst males than females and the presence of ambiguous relationships may have

300 greater costs for females than males. 
All data were analyzed using generalized linear mixed-effects regression models

302 (McCullagh and Nelder, 1989; Raudenbush and Bryk, 2002) with group as a random effect.

303 Models were run using a negative binomial distribution for IL-6, TNF- $\alpha$ and diarrhea bouts, and

304 a gamma distribution for CRP. Appropriate distribution(s) for each outcome were chosen based

305 on descriptive statistics, histograms, and Q-Q plots. We also evaluated the goodness of fit of

306 these distributions using the Pearson chi-square statistic (SAS Institute Inc., 2009). We also

307 included variables to control for known confounds: sample collection order for blood-based

308 measures, and total health observation days for diarrhea. Due to the unavailability of blood

309 samples for some animals, the cytokine and CRP analyses were run on 234 of the 252 subjects.

310 Finally, ten of the study subjects showed C-reactive protein levels above 10 (a sign of possible

311 infection), and these animals were included in analyses because they represent an important part

312 of the health continuum. We note, however, that excluding these subjects from analyses did not

313 change the magnitude or direction of the effects.

314 We used an Information Theoretic approach to determine which variables best explained

315 each of our health outcomes. First, we ran all mixed-effects regression models to address our

316 complete set of hypotheses outlined in Table 1. For each model, we present AICc scores, dAICc,

317 model likelihoods $(\mathrm{L}=\exp (-(1 / 2 * \mathrm{dAICc}))$, Akaike weights, and evidence ratios ( ratio = weight

318 of best model/ weight of comparison model) as outlined in (Burnham et al., 2011). We then used

319 model weights and dAICc to select a set of candidate models for each outcome variable. When

320 the weight of the best model was $<0.90$ (Burnham and Anderson, 2002; Symonds and

321 Moussalli, 2011), we included in the candidate set those models with dAICc $\leq 5$ and discuss the

322 inferences based on all models in this candidate set. Analyses were performed in SAS 9.4 and R

323 3.3.1 (R Core Team, 2013). Plots were produced in Stata 14.1. Although plots of model results 
324 are typically generated from marginal effects tables, this was not appropriate for our data due to

325 the presence of discontinuous regions. We have used the alternative method of generating model

326 specific plots from predicted values (Hardin and Hilbe, 2007; Rabe-Hesketh and Skrondal,

327 2012).

328

\section{Results}

Rank and Dominance Certainty. Rank and dominance certainty were associated in a nonlinear manner (Figure 2). Specifically, animals of high- and low-rank exhibited higher

332

dominance certainty than those in the middle of the rank distribution, a pattern that held true for all three study groups. In addition, there was variability in dominance certainty at each level of rank. Specifically, dominance certainty ranged from 0.70-0.97 and 0.72-0.93 among the highest and lowest ranked tertiles of the sample, respectively, which is very similar to the range for the sample as a whole (0.70-0.97).

Pro-inflammatory Measures. Results for CRP indicated a single model with the highest weight $(\mathrm{w}=0.93, \mathrm{H} 8$, Table 2$)$ in which the relationship between rank and CRP was dependent on dominance certainty and sex. High-ranking males with low dominance certainty had higher CRP, whereas little to no effect of rank was found in males with high dominance certainty (Table 3, Figure 3A). For males with highly certain dominance relationships, increasing rank by 0.25 (moving up a quartile in rank) was associated with a reduction in CRP levels by 1.17 times (Table 3, Figure 3A). In contrast, for males with low dominance certainty, increasing in rank by 0.25 was associated with a 1.80 times increase in CRP (Table 3, Figure 3A). In females there was no change in CRP with increasing rank at any level of dominance certainty (Table 3, Figure 
346 3B). Consistent with predictions, older animals also had higher levels of CRP than adults,

347 subadults, or juveniles (Table 3).

For IL-6 two models with similar weight accounted for nearly $80 \%$ of total weight (Table 4), and both models provided evidence that the effect of rank on IL-6 levels was dependent on dominance certainty $(\mathrm{w}=0.45, \mathrm{H} 5$, Figure 4$)$ and also potentially on sex $(\mathrm{w}=0.33, \mathrm{H} 8$, Figure 5). Specifically, for animals with more certain dominance relationships, an increase in rank of 0.25 was associated with 1.41 times lower levels of IL-6 (H5), an effect that may be stronger in males than in females (H8; effect size: 2.16 vs. 1.14, respectively; Table 3; Figure 5). Among animals with less certain relationships, an increase in rank of 0.25 was associated with a 1.50 times (H5) increase in IL-6 with effects possibly being stronger in males than in females (H8; effect size $=2.11$ vs. 1.24, respectively; Table 3; Figure 5). Taken together these results also indicate that high-rank animals with more ambiguous dominance relationships (i.e. low or moderate dominance certainty) exhibited higher levels of IL-6 than high-rank animals with more certain dominance relationships and that this effect may be specific to males. $\mathrm{H} 3(\mathrm{w}=0.08)$ included a main effect for dominance certainty plus age and sex terms, and indicated that an increase in dominance certainty of 0.10 was associated with 1.28 times lower levels of IL-6 (Table 3). Model H1 (w=0.06) included only age and sex terms. For all four candidate models young animals (juveniles and subadults) had lower levels of IL-6 than adults (Table 3).

For the pro-inflammatory cytokine TNF- $\alpha$, the model for H5 had the highest weight $(\mathrm{w}=$ 0.91, Table 5) indicating that the effect of rank on cytokine levels was dependent on dominance certainty for both males and females (Table 3, Figure 6). For animals with more ambiguous 
369 dominance relationships (i.e. low dominance certainty) increasing in rank by 0.25 was associated

370 with 2.07 times higher levels of TNF- $\alpha$ whereas increasing rank by 0.25 was associated with

3711.78 times decrease in TNF- $\alpha$ for animals with highly certain dominance relationships (Figure

372 6). Among low-ranked individuals, those with more certain dominance relationships had slightly

373 higher levels of TNF- $\alpha$ compared to those with lower dominance certainty. Finally, juveniles and

374 subadults had lower levels of TNF- $\alpha$ than adults (Table 3).

375 Plots of the raw data for CRP, IL-6, and TNF- $\alpha$ relative to rank and dominance certainty

376 are presented in supplemental figures S6-S8.

Diarrhea Bouts. Results for diarrhea bouts showed no single model with highest weight

Table 6). The set of candidate models included H4, H3, H7b, H2, H5 and H7a. Dominance

379 certainty was included as a main effect only (i.e. not part of interaction terms) in models H4, H3 and $\mathrm{H} 7 \mathrm{a}$ and was predictive of the incidence of diarrhea in each of these models (Table 7).

According to these models, reducing the certainty of one's dominance relationships by 0.10 (e.g., from 0.85 to 0.75 ) was associated with between 1.95 and 2.44 times greater incidence of diarrhea (Table 7), regardless of rank or sex. Models H5 and H7b were more complex, incorporating dominance certainty into interaction terms to determine whether its impact on health differed by rank or sex. The presence of these models in the candidate set suggest that the effect of dominance certainty might be dependent on rank or the effect of dominance certainty might be more pronounced in males (Table 7). However, addition of these interaction terms did not improve model fit, as AIC increased by 1.6 and 2.0 in $\mathrm{H} 7 \mathrm{~b}$ and $\mathrm{H} 5$, respectively (Table 6). Dominance rank was included as a main effect only in models $\mathrm{H} 2$, H4, and H7b (Table 6). According to these models, reducing dominance rank by 0.25 (e.g. from outranking $75 \%$ to outranking 50\%) was associated with between 1.25 and 1.42 times greater incidence of diarrhea 
392 (Table 7). Models H5 and H7a incorporated dominance rank into interaction terms with

393 dominance certainty (described above) and with sex. Addition of the dominance rank $\times$ sex

394 interaction did not improve model fit and AIC increased by 2.09 (Table 6). As expected, older

395 animals showed a higher incidence of diarrhea bouts than adults and juveniles across all models 396 (Table 7).

397

398

\section{Discussion}

A wealth of literature highlights the fact that uncertainty is a potent stressor and can lead

400

401

402

403

404

405

406

407

408

409

410

411

412

413

414 to a wide range of negative health outcomes (Baum and Fleming, 1993; Heaney et al., 1994) highlighting the potential importance of variation of dominance certainty in studies of social status. The results we present demonstrate that more complex conceptualizations of social status provide a possible explanation for seemingly contradictory findings in the status-health literature across species. The health risk for any given animal is dependent on a combination of both the individual's absolute status and a metric of the certainty or stability of that status.

The measure of relationship uncertainty used here, an average of all dyadic level dominance certainty, can also potentially offer a metric of how well an individual "fits" within the dominance hierarchy overall. Low average dominance certainty could reflect an animal that is changing in position within the hierarchy (moving up or down), or, due to the use of direct and indirect pathways in a network, low dominance certainty could also arise for an individual because others in their local community are changing their position(s) in the hierarchy. For example in Figure 1B, we can see that there is ambiguity in the likely rank relationship between animals F and I, not because they are in a direct contest with each other, but due to inconsistency in the direction of the flow of dominance in their local community (i.e. information inferred from 
415 the blue and red arrows is contradictory). A network approach can examine how instability in

416 dyadic relationships might ripple throughout a local community and potentially impact the

417 position of nearby neighbors in the network.

418 Rank and Dominance Certainty. Variation in social status, and thus its potential impact

419 on health, includes not only whether one has high or low status but also the relative predictability

420 or certainty of one's status relationships. Dominance rank and dominance certainty showed a

421 nonlinear (U-shaped) relationship where individuals of both high and low dominance rank had

422 relatively greater dominance certainty than individuals in the middle of the hierarchy. However,

423 variability in dominance certainty at all levels of dominance rank suggests that these two metrics

424 may describe two complementary aspects of social status that can have independent and

425 interacting effects on an animal's health. The idea that dominance rank stability can have a

426 critical impact on the status-health relationship has been suggested previously (Sapolsky, 1992;

427 Sapolsky, 2005; Marmot and Sapolsky, 2014). The current paper, however, expands on previous

428 research by using a more general measurement of each individual's "fit" within the group

429 hierarchy, as opposed to examining the status-health relationship in stable vs unstable groups, or

430 only in individuals that experienced dominance rank reversals.

Status and Measures of Inflammation. Our research suggests that whether individuals

432 have high or low dominance rank in the hierarchy does not fully represent the complexity with 433 which social status affects health. Instead, dominance certainty modified the impact of rank on 434 biomarkers of inflammation. Under conditions of low dominance certainty, we found that high435 ranking animals had higher levels of pro-inflammatory cytokines and CRP. This is consistent 436 with previous findings in African wild dogs, baboons, chimpanzees, dwarf mongooses, and 437 ringtail lemurs (Creel et al., 1996; Cavigelli, 1999; Muller and Wrangham, 2004; Gesquiere et 
438 al., 2011), where high dominance rank individuals (or at least the alpha individual, as in

439 Gesquiere et al., 2011) had elevated glucocorticoids. Because dominance certainty is quantified

440 as the consistency in the flow of dominance between pairs in the aggression network, having low

441 certainty may be evidence of an individual-level tendency to protest or challenge others'

442 dominance rank or precursors of a rank change (within a hierarchy that is stable overall). Thus,

443 high-ranking animals with ambiguous dominance relationships likely have reduced predictability

444 that others will submit to them and greater potential risk of losing status (e.g., Crockford et al.,

445 2008), and this type of uncertainty could represent a major psychosocial stressor. Our findings

446 are consistent with previous research indicating that instability, whether due to dominance style

447 (e.g. chimpanzees, Muller and Wrangham, 2004) or due to current social factors (e.g. baboon

448 dominance rank reversals, Sapolsky, 1992), is particularly bad for high-ranking individuals,

449 possibly due to potential for loss of status. For example, in an examination of rank reversal in

450 male baboons, Sapolsky (1992) reported that despite similar levels of participation in aggressive

451 interactions, only males about to lose their rank showed elevated GCs, not those about to rise in

452 rank.

453 In contrast, for animals with a high degree of certainty in their dominance relationships,

454 we found a small reversal of the effect with high-ranking animals having slightly lower levels of

455 inflammatory markers than low-ranking animals. This effect is weak, but notably, more closely

456 matches results from humans, baboons, macaques, meerkats, and spotted hyenas in which low

457 status individuals exhibited risky health profiles (Sapolsky and Share, 1994; Shively and

458 Clarkson, 1994; Goymann et al., 2001; Young et al., 2006; Ostner et al., 2008; Gesquiere et al.,

459 2011; Marmot and Sapolsky, 2014). In contrast to high status individuals, where uncertainty may

460 have been associated with a potential loss in status, dominance uncertainty may not be a stressor 
461 for low-status individuals because they have little to lose; it may even be the case that low-

462 ranking individuals with low dominance certainty may have an opportunity to increase their

463 status - a possibility that needs to be explored further in future studies. Among low-ranking

464 animals, being certain of one's low dominance rank is likely to be stressful because such

465 individuals can reliably expect to receive aggression, harassment, and/or intimidation from

466 dominants, have little control over the occurrence of such interactions, and have fewer social

467 outlets to cope with this harassment (Schino, 2001; Sapolsky, 2005). This is largely consistent

468 with Shively and Clarkson's findings that female macaques that were experimentally arranged to

469 lose status (via group membership manipulations) increased atherosclerosis by 500\%, whereas

470 those that gained status increased atherosclerosis by a far smaller amount $-44 \%$ (Shively and

471 Clarkson, 1994). Thus, dominance rank changes may be stressful for both parties, but losing

472 status is likely worse than gaining status.

473 Sex Differences. Although sex differences in the status-health relationship are not often

474 studied, sex differences have been noted previously (Kaplan and Manuck, 1999). Our results for

475 the pro-inflammatory proteins, CRP and IL-6, suggest that there may be sex differences in the

476 impact of rank on inflammation. Elevated levels of CRP in high-ranking individuals with lower

477 dominance certainty was found only in males, not in females. The lack of an effect for females of

478 this species is not surprising given the behavioral biology of rhesus macaques, specifically due to

479 sex differences in how dominance rank is gained and maintained. Rhesus macaque males

480 emigrate, and once they are established in a new group, they can increase their rank through both

481 alliances and direct competition. Female macaques, on the other hand, remain in their natal

482 group and inherit their dominance rank from their mothers with all the females of one family

483 outranking all the females from another family (Lindburg, 1971; Sade, 1972; Melnick et al., 
484 1984). This process results in a male hierarchy that is more labile and changeable, but changes in 485 dominance rank are rarer for females (Sade, 1972; Berard, 1990). For females, due to inherited 486 rank and lifetime tenure in social groups, we would expect to see little dominance uncertainty, 487 except during periods of larger scale group instability, such as when one matriline threatens to 488 overthrow another matriline (Ehardt and Bernstein, 1986; Beisner et al., 2011).

489 Diarrhea. Dominance uncertainty was a better predictor of diarrhea than dominance rank 490 with lower certainty being associated with greater risk of diarrhea. While animals with lower

491 492 dominance certainty may be more vulnerable to diseases causing diarrhea, stress is also a known contributor to diarrhea. It may be the case that the increased stress of uncertainty in social relationships is contributing to the incidence of non-pathogenic diarrhea (e.g., Stasi et al., 2012; Buckley et al., 2014). The small effect of dominance rank for diarrhea is consistent with other studies in baboons, macaques, meerkats, and spotted hyenas that demonstrate a wide range of negative biomarkers of health, as well as poor health outcomes in low-ranking individuals (Sapolsky and Share, 1994; Shively and Clarkson, 1994; Goymann et al., 2001; Young et al., 2006). Notably, unlike the biomarkers of inflammation discussed above, there was not strong evidence for an interaction between dominance rank and dominance certainty. This result suggests that the impact of social status on health is specific to the type of status measure being examined (e.g. certainty vs. rank) as well as the particular health or fitness outcome of interest (e.g. biomarkers of inflammation).

\section{Conclusion}

Our research demonstrates the importance of more complex representations of social status for understanding its impact on health. Our data show that the effect of social status on 
507 health is much better understood by accounting for status certainty. Indeed, the interaction

508 between a linear measure of status and status certainty in our data reconciles the contradictory

509 patterns in dominance rank and health found in the previous literature as a direct result of

510 framing social status in terms of its certainty. Our work suggests that expanding the examination

511 of the certainty of social relationships, or fit within one's social class, may be a critical step

512 toward understanding status effects on health outcomes. As such, the innovative methods leading

513 to this more complex conceptualization of status, as presented here, promises to significantly

514 enhance our ability to detect more effectively who may experience health related costs in society.

515 Our results also demonstrate that computational social network techniques have the

516 capacity to advance our understanding of the impact of social status on health by disentangling

517 the relative effects of linear measures of rank versus individual-level uncertainty of rank

518 relationships. To the best of our knowledge, we are the first to empirically demonstrate that

519 uncertainty in an individual's dominance relationships, as measured by inconsistency in the

520 direction of one's dominance network pathways, are associated with multiple indicators of

521 poorer physical well-being. In contrast, the impact of dominance rank on pro-inflammatory

522 proteins was dependent upon dominance certainty, suggesting that the effects of social status on

523 health are highly dependent on the context in which they occur.

\section{Acknowledgements}

526 We would like to thank our dedicated team that collected the behavioral and

527 physiological data (A. Barnard, T. Boussina, A. Vitale, E. Cano, J. Greco, N. Sharpe, S. Seil, J.

528 Carabez, R. Pisano, I. Wong, K. Balasubramaniam, H. Schwertscharf). We would also like to

529 thank the reviewers of this manuscript for their valuable comments and feedback. 
530

531

532

533

534

535

536

537

538

539

540

541

542

543

544

545

546

547

548

549

550

551

552

\section{References}

Abbott DH, Keverne EB, Bercovitch FB, Shively CA, Mendoza SP, Saltzman W, Snowdon CT, Ziegler TE, Banjevic M, Garland T, Jr. et al. . 2003. Are subordinates always stressed? A comparative analysis of rank differences in cortisol levels among primates. Hormones and behavior 43(1):67-82

Adler NE, Boyce T, Chesney MA, Cohen S, Folkman S, Kahn RL, and Syme SL. 1994. Socioeconomic status and health. The challenge of the gradient. The American psychologist 49(1):15-24

Albers PCH, and de Vries H. 2001. Elo-rating as a tool in the sequential estimation of dominance strengths. Animal Behaviour 61(2):489-495

Archie EA, Altmann J, and Alberts SC. 2012. Social status predicts wound healing in wild baboons. PNAS 109(23):9017-9022

Arnold W, and Dittami J. 1997. Reproductive suppression in male alpine marmots. Animal Behaviour $53(1): 53-66$

Baum A, and Fleming I. 1993. Implications of psychological research on stress and technological accidents. The American psychologist 48(6):665-672

Beisner BA, Jackson ME, Cameron AN, and McCowan B. 2011. Detecting instability in animal social networks: Genetic fragmentation is associated with social instability in rhesus macaques. PLoS ONE 6(1):e16365

Berard J. 1990. Life history patterns of male rhesus macaques on Cayo Santiago: University of Oregon Bond AB, Kamil AC, and Balda RP. 2003. Social complexity and transitive inference in corvids. Anim Behav 65(3):479-487

Boyd R, and Silk JB. 1983. A method for assigning cardinal dominance ranks. Animal Behaviour 31(1):4558 
553 Buckley MM, O'Mahony SM, and O'Malley D. 2014. Convergence of neuro-endocrine-immune pathways

554 in the pathophysiology of irritable bowel syndrome. World Journal of Gastroenterology

$555 \quad 20(27): 8846-8858$

556 Burnham KP, and Anderson DR. 2002. Model Selection and Multimodel Inference: A Practical

557 Information-Theoretic Approach. New York: Springer-Verlag

558 Burnham KP, Anderson DR, and Huyvaert KP. 2011. AIC model selection and multimodel inference in

559 behavioral ecology: some background,observations, and comparisons. Behav Ecol Sociobiol

$560 \quad 65: 23-35$

561 Cavigelli SA. 1999. Behavioural patterns associated with faecal cortisol levels in free-ranging female ring-

562 tailed lemurs, Lemur catta. Anim Behav 57:935-944

563

564

Chetty R, Stepner M, Abraham S, and et al. 2016. THe association between income and life expectancy in the united states, 2001-2014. JAMA 315(16):1750-1766

565

Creel S. 2001. Social dominance and stress hormones. Trends Ecol Evol 16(9):491-497

Creel S, Creel NM, and Monfort SL. 1996. Social stress and dominance. Nature 379:212

567

568

569

570

571

572

573

574

575

576

Creel S, Dantzer B, Goymann W, and Rubenstein DR. 2013. The ecology of stress: effects of the social environment. Funct Ecol 27:66-80

Crockford C, Wittig RM, Whitten PL, Seyfarth RA, and Cheney DL. 2008. Social stressors and coping mechanisms in wild female baboons (Papio hamadryas ursinus). Hormones and behavior 53(1):254-265

Croft DP, James R, and Krause J. 2008. Exploring animal social networks. Princeton and Oxford: Princeton University Press

Datta SB. 1986. The role of alliances in the acquisition of rank. In: Else JG, and Lee PC, editors. Primate Ontogenty, Cognition and Social Behaviour. New York: Cambridge University Press. p 219-225

Davis H. 1992. Transitive inference in rats (Rattus norvegicus). J Comp Psychol 106(4):342-349 
577 de Vries H. 1995. An improved test of linearity in dominance hierarchies containing unknown or tied

$578 \quad$ relationships. Animal Behaviour 50(5):1375-1389

579 de Vries HAN. 1998. Finding a dominance order most consistent with a linear hierarchy: a new

$580 \quad$ procedure and review. Animal Behaviour 55(4):827-843

581 Dittus W. 1975. Population dynamics of the toque monkey Macaca sinica. In: Tuttle RH, editor.

582 Socioecology and psychology of primates. Mouton: Den Haag. p 125-151

583 Ehardt C, and Bernstein I. 1986. Matrilineal overthrows in rhesus monkey groups. International Journal

$584 \quad$ of Primatology 7(2):157-181

585 Fujii K, Fushing H, Beisner BA, and McCowan B. 2014. Computing power structures in directed biosocial

586 networks: flow percolation and imputed conductance. Dept. of Statistics: University of California

$587 \quad$ Davis

588 Fujii K, Jin J, Shev A, Beisner B, McCowan B, and Fushing H. 2015. Perc: Using percolation and

589 conductance to find information flow certainty in a direct network. R package version 0.1.0 ed.

$590 \quad$ http://CRAN.R-project.org/package=Perc

591 Fushing H, McAssey M, and McCowan B. 2011a. Computing a ranking network with confidence bounds

592 from a graph-based Beta random field. Proc R Soc 467(2136):3590-3612

593 Fushing H, McAssey MP, Beisner B, and McCowan B. 2011b. Ranking network of a captive rhesus

594 macaque society: a sophisticated corporative kingdom. PLoS ONE 6(3):e17817

595 Gesquiere LR, Learn NH, Simao MCM, Onyango PO, Alberts SC, and Altmann J. 2011. Life at the Top:

596 Rank and Stress in Wild Male Baboons. Science 333(6040):357-360

597 Goymann W, East ML, Wachter B, Höner OP, Möstl E, Van't Holf TJ, and Hofer H. 2001. Social state-

598 dependent and environmental modulation of faecal corticosteroid levels in free-ranging female

$599 \quad$ spotted hyenas. Proc R Soc B 268:2453-2459 
600 Grosenick L, Clement TS, and Fernald RD. 2007. Fish can infer social rank by observation alone. Nature

601 445(7126):429-432

602

603

604

605

606

607

608

609

610

611

612

613

614

615

616

617

618

619

620

621

622

623

Habig B, and Archie EA. 2015. Social status, immune response and parasitism in males: a meta-analysis. Philos Trans R Soc Lond B Biol Sci 370(1669)

Hackländer K, Möstl E, and Arnold W. 2003. Reproductive suppression in female Alpine marmots, Marmota marmota. Anim Behav 65(6):1133-1140

Hardin JW, and Hilbe J. 2007. Generalized linear models and extensions. College Station, Tex.: Stata Press. $x x i i, 387$ p. $p$

Hawkley LC, and Capitanio JP. 2015. Perceived social isolation, evolutionary fitness and health outcomes: a lifespan approach. Philos Trans R Soc Lond B Biol Sci 370(1669)

Heaney CA, Israel BA, and House JS. 1994. Chronic job insecurity among automobile workers: Effects on job satisfaction and health. Social science \& medicine 38(10):1431-1437

Hinde RA. 1976. Interactions, Relationships and Social-Structure. Man 11(1):1-17

Hostinar CE, Sullivan RM, and Gunnar MR. 2014. Psychobiological mechanisms underlying the social buffering of the hypothalamic-pituitary-adrenocortical axis: a review of animal models and human studies across development. Psychological bulletin 140(1):256-282

Kaplan JR, and Manuck SB. 1999. Status, stress, and atherosclerosis: the role of environment and individual behavior. Annals of the New York Academy of Sciences 896:145-161

Klein SL. 2000. The effects of hormones on sex differences in infection: from genes to behavior. Neuroscience \& Biobehavioral Reviews 24(6):627-638

Libby P, Ridker PM, and Maseri A. 2002. Inflammation and Atherosclerosis. Circulation 105(9):1135-1143 Lindburg DG. 1971. The rhesus monkey in north India: An ecological and behavioral study. In: Rosenblum LA, editor. Primate behavior: Development in field and laboratory research. New York: Academic Press. p 1-106 
624 Lynch JW, Ziegler TE, and Strier KB. 2002. Individual and Seasonal Variation in Fecal Testosterone and 625 Cortisol Levels of Wild Male Tufted Capuchin Monkeys, Cebus apella nigritus. Horm Behav $626 \quad 41(3): 275-287$

627 628

629

630

631

632

633

634

635

636

637

638

639

640

641

642

643

644

645

646

647

Marmot M, and Sapolsky RM. 2014. Of Baboons and Men: Social Circumstances, Biology, and the Social Gradient in Health. In: Weinstein M, and Lane MA, editors. Sociality, Hierarchy, Health: Comparative Biodemography: A collection of papers. Washington, D. C.: The National Academies Press. p 365-388

Mays NA, Vleck CM, and Dawson J. 1991. Plasma luteinizing hormone, steroid hormones, behavioral role and nesting stage in the cooperatively breeding Harris's hawk (Parabuteo unicinctus). Auk 108:619

McCullagh P, and Nelder JA. 1989. Generalized Linear Models. London: Chapman and Hall McGonigle BO, and Chalmers M. 1977. Are monkeys logical? Nature 267(5613):694-696

Melnick DJ, Pearl MC, and Richard AF. 1984. Male migration and inbreeding avoidance in wild rhesus monkeys. American Journal of Primatology 7(3):229-243

Muggeo VMR. 2008. segmented: an R package to fit regression models with broken-line relationships. $R$ News 8(1):20-25

Muller MN, and Wrangham RW. 2004. Dominance, cortisol, and stress in wild chimpanzees (Pan troglodytes). Behav Ecol Sociobiol 55:332-340

Neumann C, Duboscq J, Dubuc C, Ginting A, Irwan AM, Agil M, Widdig A, and Engelhardt A. 2011. Assessing dominance hierarchies: validation and advantages of progressive evaluation with Elorating. Anim Behav 82(4):911-921

Nunn CL, Craft ME, Gillespie TR, Schaller M, and Kappeler PM. 2015. The sociality-health-fitness nexus: synthesis, conclusions and future directions. Philosophical Transactions of the Royal Society of London B: Biological Sciences 370(1669) 
648 Ostner J, Heistermann M, and Schülke O. 2008. Dominance, aggression, and physiological stress in wild male Assamese macaques (Macaca assamensis). Horm Behav 54:613-619

650

651

652

653

654

655

656

657

658

659

660

661

662

663

664

665

666

667

668

669

670

671

Pachucki MC, Ozer EJ, Barrat A, and Cattuto C. 2015. Mental health and social networks in early adolescence: a dynamic study of objectively-measured social interaction behaviors. Social science \& medicine 125:40-50

Perkins JM, Subramanian SV, and Christakis NA. 2015. Social networks and health: a systematic review of sociocentric network studies in low- and middle-income countries. Social science \& medicine $125: 60-78$

Pradhan AD, Manson JE, Rifai N, Buring JE, and Ridker PM. 2001. C-reactive protein, interleukin 6, and risk of developing type 2 diabetes mellitus. JAMA : the journal of the American Medical Association 286(3):327-334

R Core Team. 2013. R: A language and environment for statistical computing. Vienna, Austria: R Foundation for Statistical Computing

Rabe-Hesketh S, and Skrondal A. 2012. Multilevel and longitudinal modeling using Stata: Continuous responses. College Station, Tex.: Stata Press Publication. 497 p

Raudenbush SW, and Bryk AS. 2002. Hierarchical Linear Models: Applications and data analysis methods. Thousand Oaks: Sage Publications

Sade DS. 1972. A longitudinal study of social behavior of rhesus monkeys. In: Tuttle R, editor. The Functional and Evolutionary Biology of Primates. Chicago: Aldine-Atherton. p 378-398

Sansoni P, Vescovini R, Fagnoni F, Biasini C, Zanni F, Zanlari L, Telera A, Lucchini G, Passeri G, Monti D et al. . 2008. The immune system in extreme longevity. Experimental Gerontology 43(2):61-65

Sapolsky RM. 1992. Cortisol concentrations and the social significance of rank instability among wild baboons. Psychoneuroendocrinology 17:701-709

Sapolsky RM. 2005. The influence of social hierarchy on primate health. Science 308(5722):648-652 
672 Sapolsky RM, and Mott GE. 1987. Social subordinance in wild baboons is associated with suppressed

673

674

675

676

677

678

679

680

681

682

683

684

685

686

687

688

689

690

691

692

693

694

high density lipoprotein-cholesterol concentrations: The possible role of chronic social stress. Endocrinology 121(5):1605-1610

Sapolsky RM, Romero LM, and Munck AU. 2000. How do glucocorticoids influence stress responses? Integrating permissive, suppressive, stimulatory, and preparative actions. Endocrine reviews $21(1): 55-89$

Sapolsky RM, and Share LJ. 1994. Rank-related differences in cardiovascular function among wild baboons: Role of sensitivity to glucocorticoids. American Journal of Primatology 32(4):261-275

SAS Institute Inc. 2009. SAS/STAT ${ }^{\circledR} 9.2$ User’s Guide. Cary, NC: SAS Institute Inc.

Schino G. 2001. Grooming, competition and social rank among female primates: a meta-analysis. Anim Behav 62(2):265-271

Schoech SJ, Mumme RL, and Moore MC. 1991. Reproductive endocrinology and mechanisms of breeding inhibition in cooperatively breeding Florida scrub jays, Aphelocoma c. coerulescens. Condor $93: 354-364$

Sebastian SO. 2015. Using individual attributes to predict hierarchical position in a Macaca sylvanus group at 'La forêt des singes', Rocamadour. Behavioural Processes 111:109-117

Shively CA, and Clarkson TB. 1994. Social status and coronary artery atherosclerosis in female monkeys. Arteriosclerosis and thrombosis : a journal of vascular biology / American Heart Association $14(5): 721-726$

Sprague DS. 1992. Life history and male intertroop mobility among Japanese macaques (Macaca fuscata). International Journal of Primatology 13(4):437-454

Sprague DS. 1998. Age, dominance rank, natal status, and tenure among male macaques. American Journal of Physical Anthropology 105(4):511-521 
695 Stasi C, Rosselli M, Bellini M, Laffi G, and Milani S. 2012. Altered neuro-endocrine-immune pathways in

696 the irritable bowel syndrome: the top-down and the bottom-up model. Journal of

697 Gastroenterology 47(11):1177-1185

698 Symonds MRE, and Moussalli A. 2011. A brief guide to model selection, multimodel inference and model

699 averaging in behavioural ecology using Akaike's information criterion. Behav Ecol Sociobiol

$700 \quad 65: 13-21$

701 Thoits PA. 2011. Mechanisms linking social ties and support to physical and mental health. Journal of 702 health and social behavior 52(2):145-161

703 Viswanath G. 2016. Age and the Elo Rating System, how underrated are the kids?

704 Wingfield JC, Hegner RE, and Lewis DM. 1991. Circulating levels of luteinizing hormone and steroid 705

706 hormones in relation to social status in the cooperatively breeding white-browed sparrow weaver, Plocepasser mahali. J Zool 225:43-58

707

Young AJ, Carlson AA, Monfort SL, Russell AF, Bennett NC, and Clutton-Brock T. 2006. Stress and the 708 suppression of subordinate reproduction in cooperatively breeding meerkats. PNAS

709 103(32):12005-12010

710

711

712 
713 Figure Legends

714 Figure 1: Inference of dominance rank and certainty using a network.

715 A) Although animals A and D do not directly interact, it can be inferred that A outranks D

716 through the indirect pathways in the network. Certainty for this inference is increased when

717 multiple pathways flow in the same direction (i.e. from A to D). B) Although animals F and I do

718 not interact, it can be inferred through the most direct pathway (through individual J) that I

719 outranks F. Certainty for this inference, however, is lower due to the contradictory flow of

720 dominance from $\mathrm{F}$ to I (through individuals $\mathrm{G}$ and $\mathrm{H}$ ).

721

722

Figure 2. Dominance rank and dominance certainty

723 Scatter plot of dominance rank and dominance certainty. Markers indicate group membership.

724

725

Figure 3. Sex differences in the impact of dominance certainty and rank on inflammation

based on serum levels of C-reactive protein (CRP).

727

Predicted values of CRP. Panels A and B depict effects for CRP for males and females,

respectively (based on model H8). Separate lines represent the interaction between dominance

729 rank and dominance certainty.

730

731

Figure 4. The impact of dominance certainty and rank on inflammation based on serum

732 levels of interleukin-6 (IL-6).

733

Predicted values of IL-6 based on model H-5. Separate lines represent the interaction between dominance rank and dominance certainty. 
736 Figure 5. Sex differences in the impact of dominance certainty and rank on inflammation

737 based on serum levels of interleukin-6 (IL-6).

738 Predicted values of IL-6 based on model H8. Panels A and B depict effects for IL-6 for males

739 and females, respectively. Separate lines represent the interaction between dominance rank and

740 dominance certainty.

741 Figure 6. Dominance certainty moderates the effect of rank on TNF- $\alpha$

742 Predicted values for TNF- $\alpha$ based on model H5. Separate lines represent the interaction between

743 rank and dominance certainty. 


\section{Figure 1}

Inference of dominance rank and certainty using a network.

A) Although animals $A$ and $D$ do not directly interact, it can be inferred that $A$ outranks $D$ through the indirect pathways in the network. Certainty for this inference is increased when multiple pathways flow in the same direction (i.e. from A to D). B) Although animals $F$ and I do not interact, it can be inferred through the most direct pathway (through individual J) that I outranks F. Certainty for this inference, however, is lower due to the contradictory flow of dominance from $\mathrm{F}$ to I (through individuals $\mathrm{G}$ and $\mathrm{H}$ ).
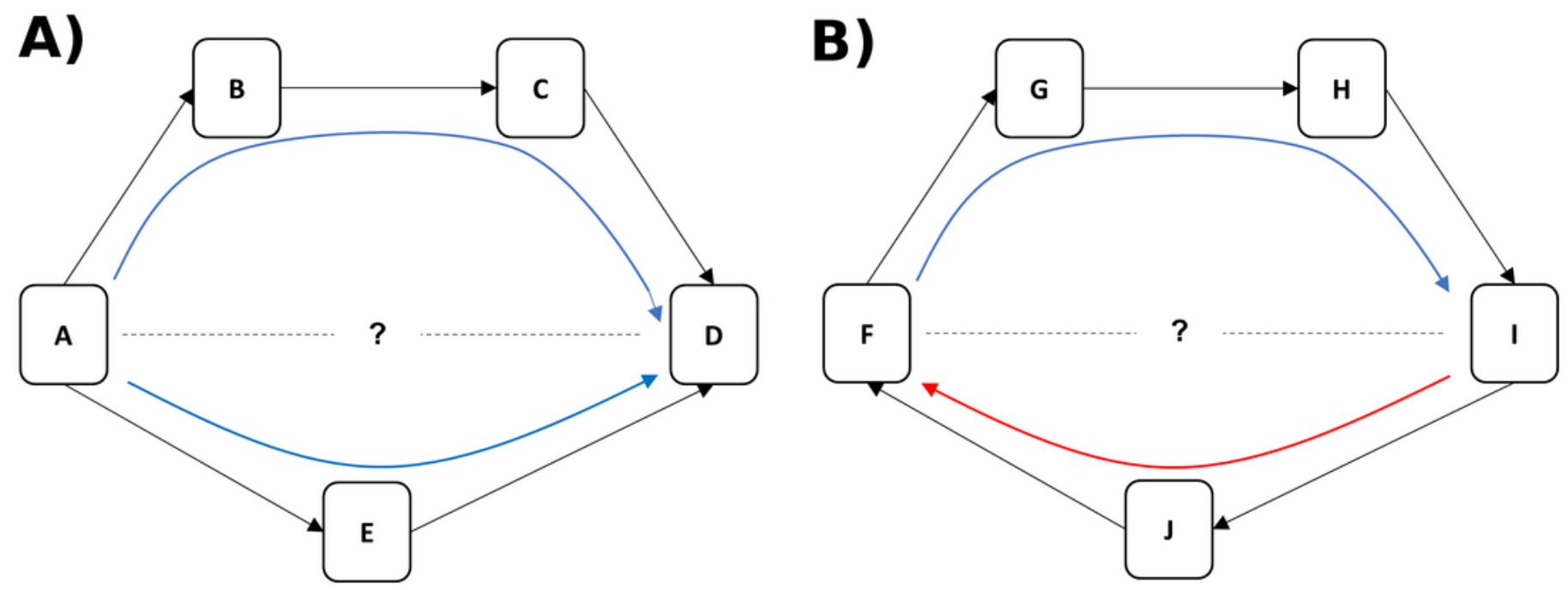
Figure 2

Rank and dominance certainty

Scatter plot of rank and dominance certainty. Markers indicate group membership.

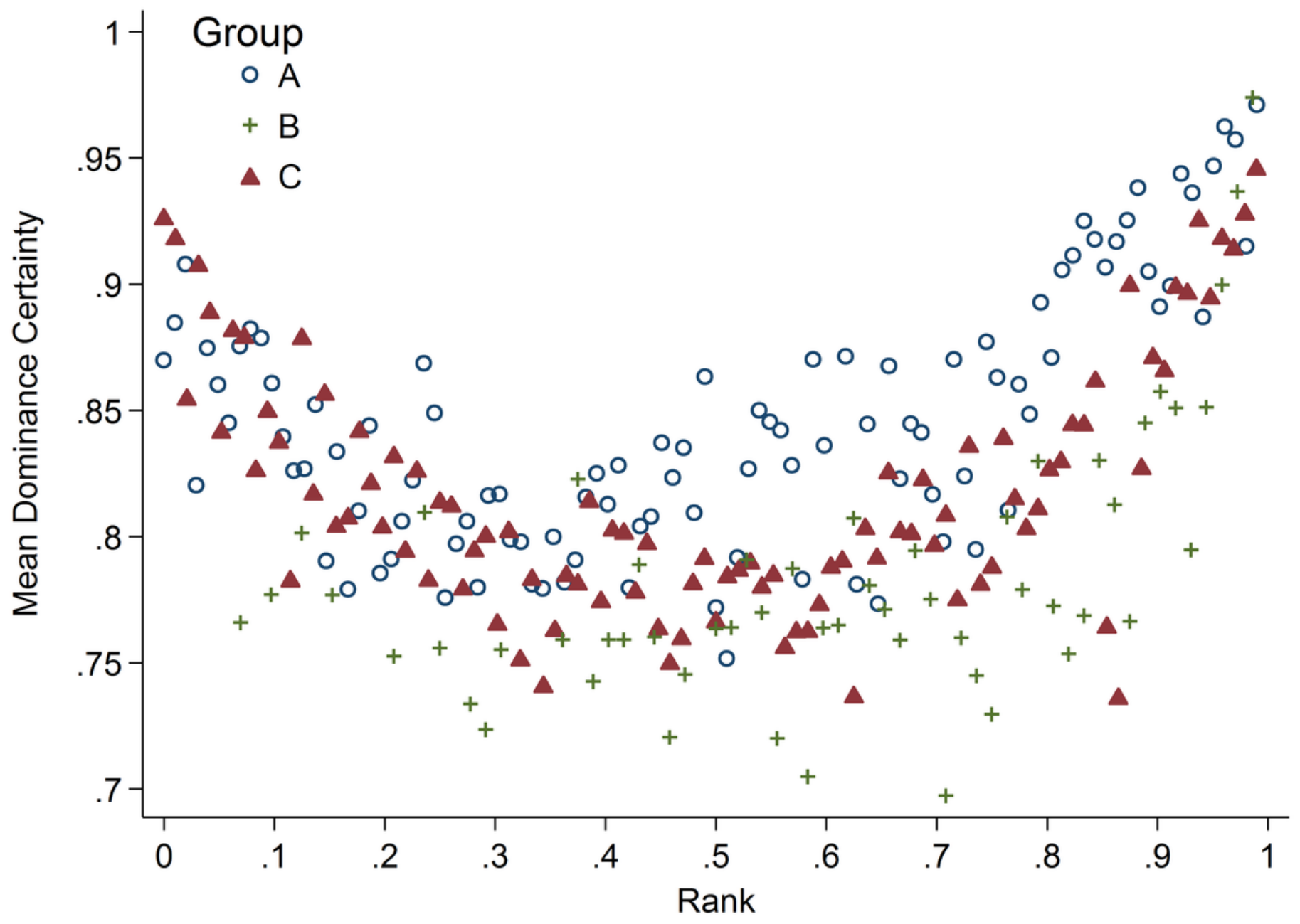


Figure 3

Sex differences in the impact of dominance certainty and rank on CRP

Predicted values of CRP. Panels A and B depict effects for CRP for males and females, respectively (based on model $\mathrm{H} 8$ ). Separate lines represent the interaction between dominance rank and dominance certainty.

A)

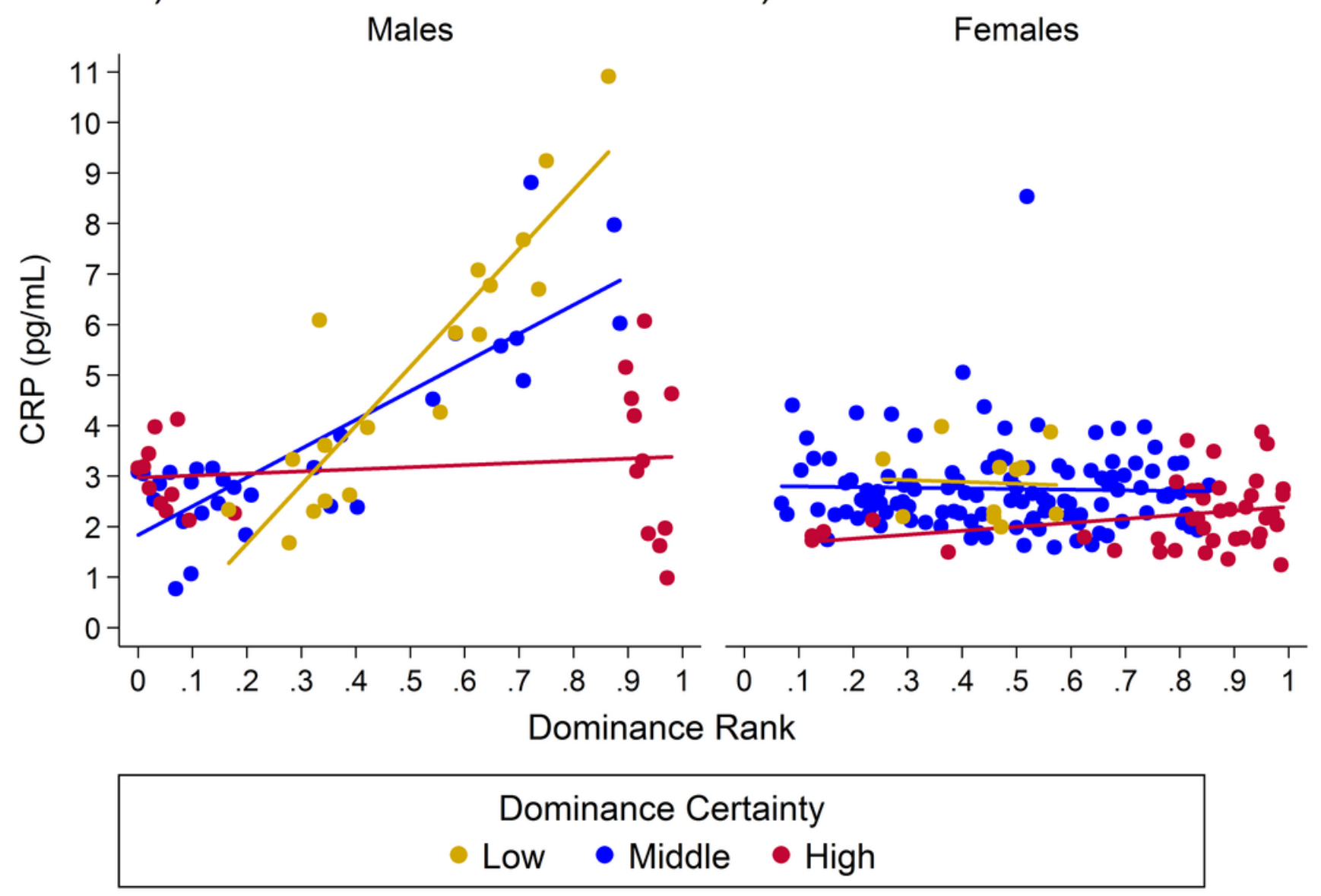


Figure 4

The impact of dominance certainty and rank on inflammation based on serum levels of interleukin-6 (IL-6)

Predicted values of IL-6 based on model H-5. Separate lines represent the interaction between dominance rank and dominance certainty

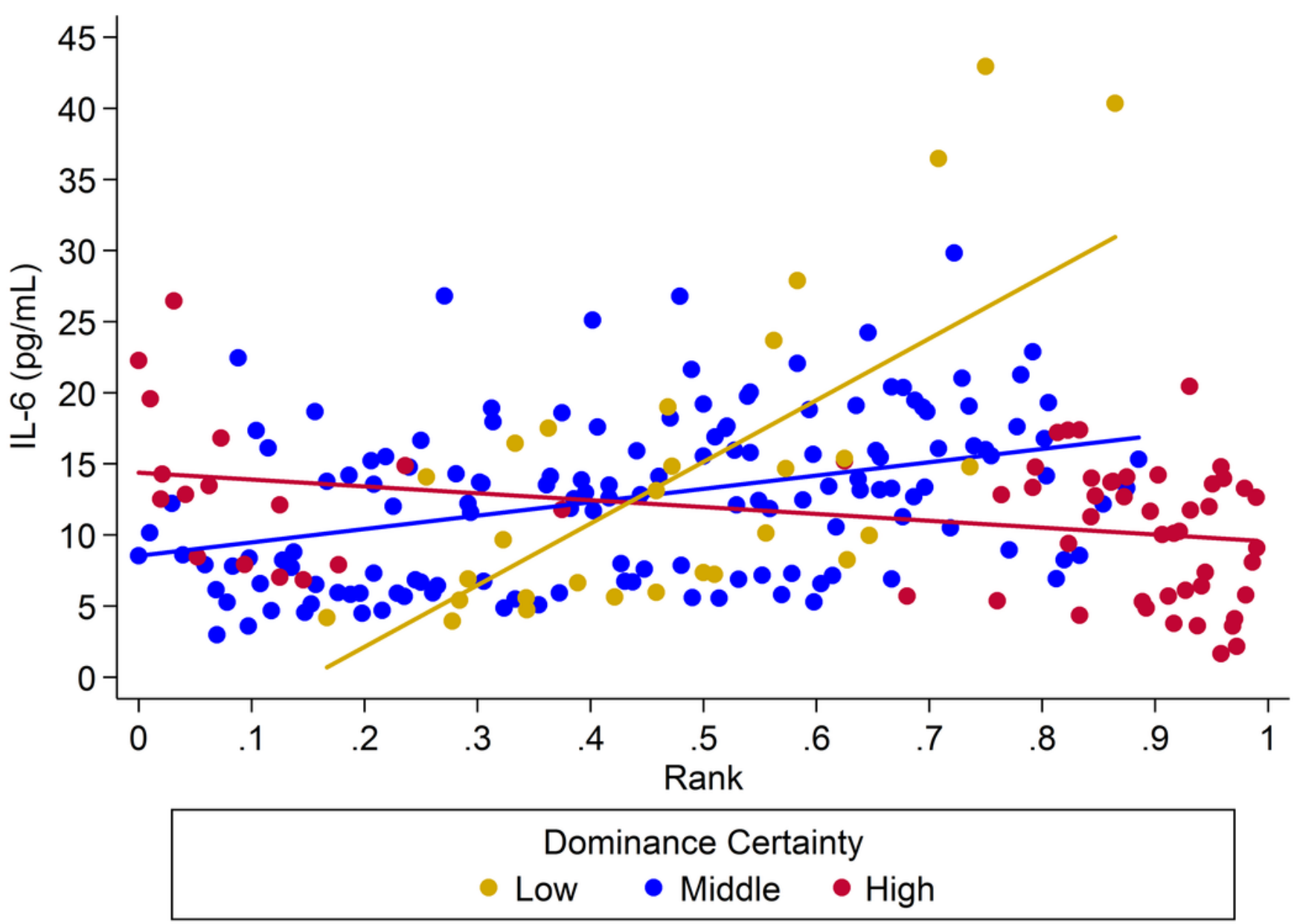


Figure 5

Sex differences in the impact of dominance certainty and rank on inflammation based on serum levels of interleukin-6 (IL-6)

Predicted values of IL- 6 based on model H8. Panels A and B depict effects for IL-6 for males and females, respectively. Separate lines represent the interaction between dominance rank and dominance certainty.

A)

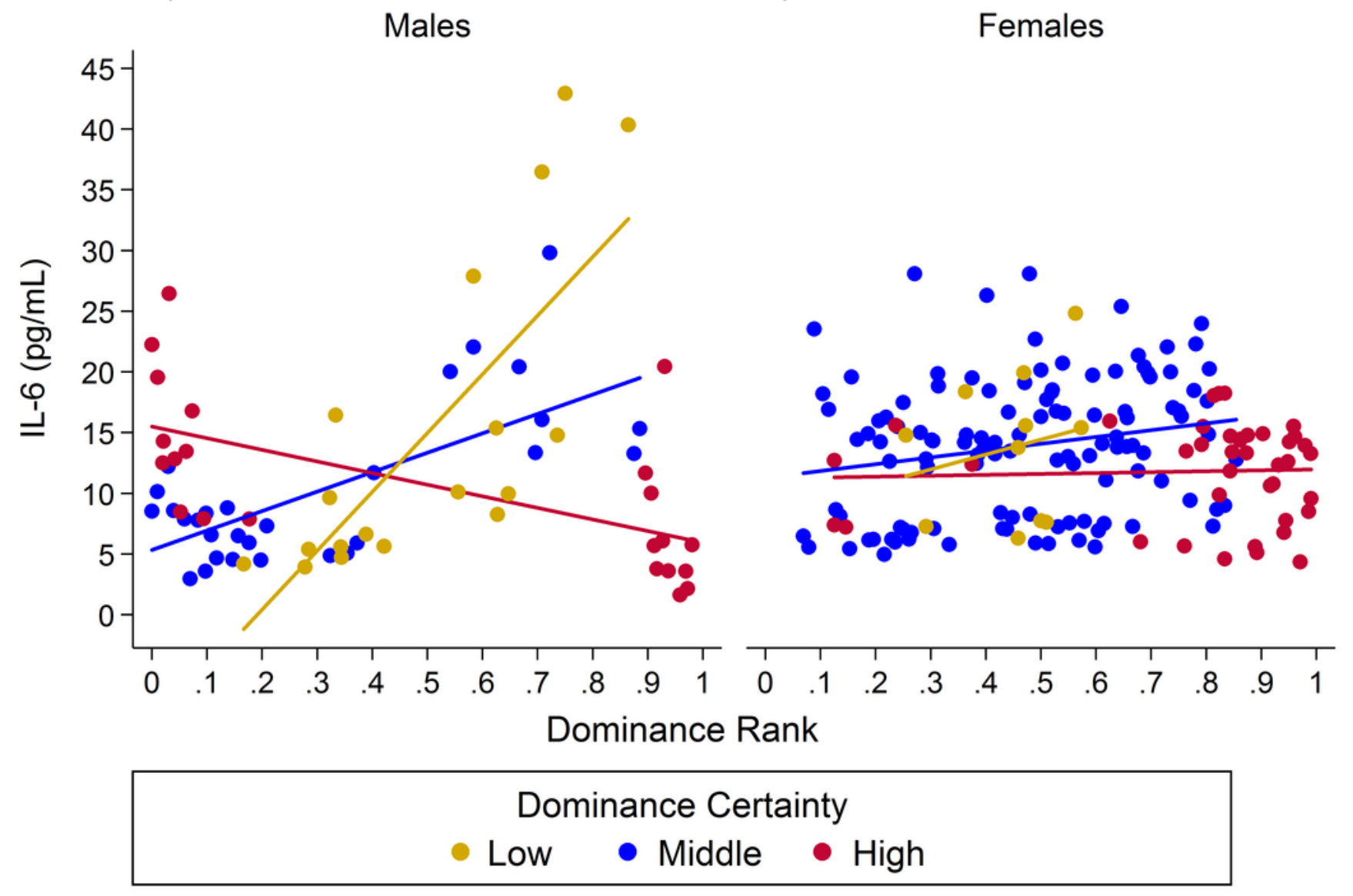


Figure 6

Dominance certainty moderates the effect of rank on TNF- $\alpha$

Predicted values for TNF- $\alpha$ based on model H5. Separate lines represent the interaction between rank and dominance certainty.

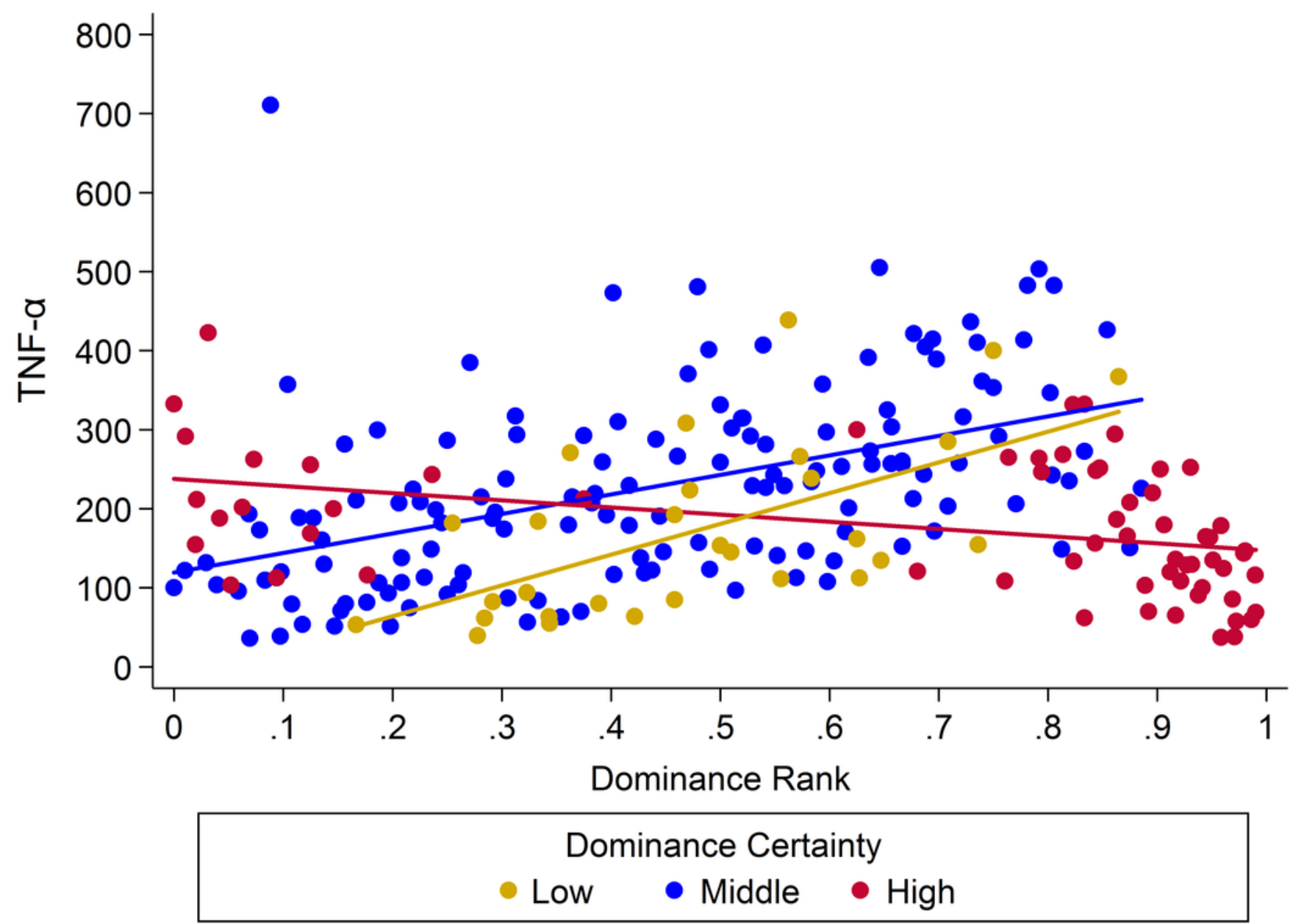


Table $\mathbf{1}$ (on next page)

Hypotheses 
1 Table 1: Hypotheses

\begin{tabular}{|c|c|c|}
\hline Hypothesis & Question & Variables \\
\hline HO & Null Model & $\mathrm{Y}=$ control variables \\
\hline $\mathrm{H} 1$ & Does health differ by age or sex class? & $Y=$ sex + age \\
\hline $\mathrm{H} 2$ & $\begin{array}{l}\text { Does rank influence health beyond effects of age and } \\
\text { sex? }\end{array}$ & $Y=$ sex + age + rank \\
\hline H3 & $\begin{array}{l}\text { Does dominance certainty influence health beyond } \\
\text { effects of age and sex? }\end{array}$ & $Y=$ sex + age $+D C$ \\
\hline $\mathrm{H} 4$ & $\begin{array}{l}\text { What are the relative impacts of rank and dominance } \\
\text { certainty on health? }\end{array}$ & $Y=$ sex + age + rank $+D C$ \\
\hline H5 & $\begin{array}{l}\text { Does the impact of rank on health depend upon } \\
\text { dominance certainty? }\end{array}$ & $\begin{array}{l}Y=\text { sex }+ \text { age }+ \text { rank }+D C+ \\
\text { rank }^{*} D C\end{array}$ \\
\hline H6 & $\begin{array}{l}\text { Does the impact of rank differ for juveniles, adults } \\
\text { and geriatric animals? }\end{array}$ & $Y=$ sex + age + rank + rank*age \\
\hline $\mathrm{H7a}$ & $\begin{array}{l}\text { Does the impact of status (i.e. rank) differ for males } \\
\text { and females? }\end{array}$ & $Y=\operatorname{sex}+$ age + rank + rank*sex \\
\hline $\mathrm{H} 7 \mathrm{~b}$ & $\begin{array}{l}\text { Does the impact of status (i.e. dominance certainty) } \\
\text { differ for males and females? }\end{array}$ & $Y=$ sex + age + rank $+D C^{*}$ sex \\
\hline $\mathrm{H} 8$ & $\begin{array}{l}\text { Due to sex differences in how status is attained, does } \\
\text { the interaction of rank and DC affect males and } \\
\text { females differently? }\end{array}$ & $\begin{array}{l}Y=\text { sex }+ \text { age }+ \text { rank }+D C+ \\
\text { sex*rank }+ \text { sex*DC }+ \text { rank*DC }+ \\
\text { sex*DC*rank }\end{array}$ \\
\hline
\end{tabular}

2 All models include a random effect of cage. DC: dominance certainty 
Table 2 (on next page)

Model fitting for C-reactive protein 
1 Table 2: Model fitting for C-reactive protein

\begin{tabular}{|c|c|c|c|c|c|c|}
\hline & Model & $\mathrm{AICc}$ & $\triangle \mathrm{AICc}$ & $\begin{array}{l}\text { Model } \\
\text { Likelihood }\end{array}$ & $\begin{array}{l}\text { Model } \\
\text { Weight }\end{array}$ & $\begin{array}{l}\text { Evidence } \\
\text { Ratio }\end{array}$ \\
\hline H8 & $\begin{array}{l}\mathrm{Y}=\mathrm{SO}+\mathrm{IL}-6+\mathrm{sex}+\text { age + rank + DC + rank*DC } \\
+ \text { rank*sex + DC*sex + sex*rank*DC }\end{array}$ & 1022.74 & 0.00 & 1.000 & 0.930 & 1.00 \\
\hline H5 & $\mathrm{Y}=\mathrm{SO}+\mathrm{IL}-6+$ sex + age + rank $+\mathrm{DC}+$ rank $* \mathrm{DC}$ & 1029.58 & 6.84 & 0.033 & 0.030 & 30.55 \\
\hline $\mathrm{H} 7 \mathrm{a}$ & $\mathrm{Y}=\mathrm{SO}+\mathrm{IL}-6+$ sex + age + rank $+\mathrm{DC}+$ rank$^{*}$ sex & 1030.86 & 8.12 & 0.017 & 0.016 & 57.94 \\
\hline $\mathrm{H} 4$ & $\mathrm{Y}=\mathrm{SO}+\mathrm{IL}-6+\mathrm{sex}+\mathrm{age}+$ rank + DC & 1031.87 & 9.13 & 0.010 & 0.010 & 95.83 \\
\hline H3 & $\mathrm{Y}=\mathrm{SO}+\mathrm{IL}-6+\mathrm{sex}+$ age $+\mathrm{DC}$ & 1032.62 & 9.88 & 0.007 & 0.007 & 139.82 \\
\hline $\mathrm{H} 7 \mathrm{~b}$ & $\mathrm{Y}=\mathrm{SO}+\mathrm{IL}-6+\mathrm{sex}+$ age + rank $+\mathrm{DC}+\mathrm{DC} *$ sex & 1033.29 & 10.55 & 0.005 & 0.005 & 195.28 \\
\hline $\mathrm{H} 1$ & $\mathrm{Y}=\mathrm{SO}+\mathrm{IL}-6+\mathrm{sex}+\mathrm{age}$ & 1036.40 & 13.66 & 0.001 & 0.001 & 923.19 \\
\hline H6 & $\mathrm{Y}=\mathrm{SO}+\mathrm{IL}-6+$ sex + age + rank $+\mathrm{DC}+$ rank$^{*}$ age & 1037.00 & 14.26 & 0.001 & 0.001 & 1246.43 \\
\hline $\mathrm{H} 2$ & $\mathrm{Y}=\mathrm{SO}+\mathrm{IL}-6+$ sex + age + rank & 1037.85 & 15.11 & 0.001 & 0.000 & 1910.99 \\
\hline $\mathrm{HO}$ & $Y=S O+I L-6$ & 1044.31 & 21.57 & 0.000 & 0.000 & 48356.29 \\
\hline
\end{tabular}

2 Random effect: Cage; $\mathrm{N}=234$; SO: Sampling order; DC: Dominance certainty 


\section{Table 3(on next page)}

Model coefficients and SEs from the sets of candidate models for pro-inflammatory proteins.

${ }^{1} \mathrm{DC}$ : Dominance certainty. ${ }^{2}$ Males were referent category. ${ }^{3}$ Sampling order. ${ }^{4} \mathrm{Adults}$ (6-12 yr) were the referent category. $* p<0.05 ;{ }^{+} p<0.1$ 
1 Table 3: Model coefficients and SEs from the sets of candidate models for pro-inflammatory proteins

\begin{tabular}{|c|c|c|c|c|c|c|}
\hline & $\begin{array}{l}\text { CRP }(\mathrm{H} 8) \\
\text { coeff (SE) }\end{array}$ & $\begin{array}{l}\text { IL-6 (H5) } \\
\text { coeff (SE) }\end{array}$ & $\begin{array}{l}\text { IL-6 (H8) } \\
\text { coeff (SE) }\end{array}$ & $\begin{array}{l}\text { IL-6 (H3) } \\
\text { coeff (SE) }\end{array}$ & $\begin{array}{l}\text { IL-6 (H1) } \\
\text { coeff (SE) }\end{array}$ & $\begin{array}{l}\text { TNF- } \alpha(\mathrm{H} 5) \\
\text { coeff (SE) }\end{array}$ \\
\hline $\mathrm{dAICc}$ & 0 & 0 & 0.62 & 3.54 & 3.90 & 0 \\
\hline Intercept & $2.48(2.34)$ & $-3.71(3.15)$ & $0.65(4.74)$ & $4.40(1.23)$ & $2.46(0.20)$ & $-6.34(3.87)$ \\
\hline Rank & $-0.08(3.10)$ & $12.6(4.48)^{*}$ & $5.89(6.23)$ & -- & -- & $22.0(5.71)^{*}$ \\
\hline $\mathrm{DC}^{1}$ & $-1.79(2.86)$ & $7.35(3.81)^{+}$ & $1.98(5.79)$ & $-2.46(1.53)^{+}$ & -- & $13.9(4.70)^{*}$ \\
\hline Sex ${ }^{2}$ & $-5.70(3.12)^{+}$ & $0.034(0.19)$ & $-8.79(6.58)$ & $0.18(0.18)$ & $0.18(0.18)$ & $-0.4(0.25)$ \\
\hline Rank $\times$ DC & $0.11(3.72)$ & $-15.0(5.30)^{*}$ & $-6.88(7.44)$ & -- & -- & $-26.2(6.75)^{*}$ \\
\hline Rank $\times \operatorname{Sex}^{2}$ & $13.2(4.57)$ * & -- & $19.3(9.51)^{*}$ & -- & -- & -- \\
\hline $\mathrm{DC} \times \mathrm{Sex}^{2}$ & $6.75(3.77)^{+}$ & -- & $10.7(7.96)$ & -- & -- & -- \\
\hline Rank $\times \mathrm{DC} \times \mathrm{Sex}^{2}$ & $-14.9(5.41)^{*}$ & -- & $-23.5(11.2) *$ & -- & -- & -- \\
\hline IL-6 & $0.004(0.002)$ & -- & -- & -- & -- & -- \\
\hline $\mathrm{SO}^{3}$ & $0.026(0.02)^{+}$ & $0.053(0.03)^{+}$ & $0.054(0.03)^{+}$ & $0.051(0.03)^{+}$ & $0.041(0.03)$ & $0.061(0.03)^{+}$ \\
\hline Age $^{4}-3 \mathrm{yr}$ & $-0.004(0.12)$ & $-0.66(0.25)^{*}$ & $-0.68(0.25)^{*}$ & $-0.64(0.23) *$ & $0.65(0.23)^{*}$ & $-0.47(0.34)$ \\
\hline Age- 4-5 yr & $-0.046(0.11)$ & $-0.88(0.21)^{*}$ & $-0.88(0.21)^{*}$ & $-0.82(0.21)^{*}$ & $-0.82(0.21)^{*}$ & $-0.83(0.28)^{*}$ \\
\hline Age-13+yr & $0.27(0.13)^{*}$ & $0.24(0.25)$ & $0.31(0.25)$ & $0.16(0.25)$ & $0.11(0.26)$ & $0.33(0.35)$ \\
\hline
\end{tabular}

$2 \quad{ }^{1}$ DC: Dominance certainty. ${ }^{2}$ Males were referent category. ${ }^{3}$ Sampling order. ${ }^{4}$ Adults (6-12 yr) were the

3 referent category.

$4 \quad * p<0.05 ;{ }^{+} p<0.1$ 


\section{Table 4(on next page)}

Model fitting for IL-6 
1 Table 4: Model fitting for IL-6

\begin{tabular}{|c|c|c|c|c|c|c|}
\hline & Model & $\mathrm{AICc}$ & $\triangle \mathrm{AICc}$ & $\begin{array}{l}\text { Model } \\
\text { Likelihood }\end{array}$ & $\begin{array}{l}\text { Model } \\
\text { Weight }\end{array}$ & $\begin{array}{l}\text { Evidence } \\
\text { Ratio }\end{array}$ \\
\hline H5 & $\mathrm{Y}=\mathrm{SO}+\mathrm{sex}+$ age + rank $+\mathrm{DC}+$ rank $^{*} \mathrm{DC}$ & 1626.20 & 0.00 & 1.000 & 0.451 & 1.00 \\
\hline $\mathrm{H} 8$ & $\begin{array}{l}Y=S O+\text { sex }+ \text { age }+ \text { rank }+D C+\text { rank*DC } \\
+ \text { rank*sex }+D C^{*} \text { sex }+ \text { sex*rank*DC }\end{array}$ & 1626.81 & 0.61 & 0.737 & 0.332 & 1.36 \\
\hline H3 & $Y=S O+$ sex + age $+D C$ & 1629.74 & 3.54 & 0.170 & 0.077 & 5.88 \\
\hline $\mathrm{H} 1$ & $\mathrm{Y}=\mathrm{SO}+\mathrm{sex}+$ age & 1630.10 & 3.90 & 0.143 & 0.064 & 7.02 \\
\hline $\mathrm{H} 4$ & $Y=S O+$ sex + age + rank + DC & 1631.86 & 5.66 & 0.059 & 0.027 & 16.96 \\
\hline $\mathrm{H} 2$ & $\mathrm{Y}=\mathrm{SO}+\mathrm{sex}+$ age + rank & 1632.17 & 5.97 & 0.050 & 0.023 & 19.81 \\
\hline $\mathrm{H7a}$ & $\mathrm{Y}=\mathrm{SO}+\mathrm{sex}+$ age + rank $+\mathrm{DC}+$ rank*sex $^{*}$ & 1633.32 & 7.12 & 0.028 & 0.013 & 35.16 \\
\hline $\mathrm{H} 7 \mathrm{~b}$ & $Y=S O+$ sex + age + rank $+D C+D C^{*} \operatorname{sex}$ & 1634.07 & 7.86 & 0.020 & 0.009 & 51.01 \\
\hline H6 & $\mathrm{Y}=\mathrm{SO}+$ sex + age + rank $+\mathrm{DC}+$ rank*age & 1635.03 & 8.83 & 0.012 & 0.005 & 82.66 \\
\hline HO & $\mathrm{Y}=\mathrm{SO}$ & 1641.48 & 15.28 & 0.000 & 0.000 & 2079.21 \\
\hline
\end{tabular}

2 Random effect: Cage; $\mathrm{N}=234$; SO: Sampling order; DC: Dominance certainty; 


\section{Table 5 (on next page)}

Model fitting for TNF- $\alpha$ 
1 Table 5: Model fitting for TNF- $\alpha$

\begin{tabular}{|c|c|c|c|c|c|c|}
\hline & Model & $\mathrm{AICC}$ & $\triangle \mathrm{AICc}$ & $\begin{array}{l}\text { Model } \\
\text { Likelihood }\end{array}$ & $\begin{array}{l}\text { Model } \\
\text { Weight }\end{array}$ & $\begin{array}{l}\text { Evidence } \\
\text { Ratio }\end{array}$ \\
\hline H5 & $Y=S O+$ sex + age + rank $+D C+$ rank$^{*} D C$ & 2722.67 & 0.00 & 1.000 & 0.907 & 1 \\
\hline H8 & $\begin{array}{l}Y=S O+s e x+a g e+r a n k+D C+r^{\prime} k^{*} D C \\
+ \text { rank}^{*} \text { sex }+D C^{*} \text { sex }+ \text { sex*rank*DC }\end{array}$ & 2728.28 & 5.61 & 0.061 & 0.055 & 16.52 \\
\hline $\mathrm{H} 1$ & $Y=S O+$ sex + age & 2731.06 & 8.39 & 0.015 & 0.014 & 66.39 \\
\hline HO & $Y=S O$ & 2732.14 & 9.47 & 0.009 & 0.008 & 113.64 \\
\hline H3 & $Y=S O+$ sex + age $+D C$ & 2732.42 & 9.76 & 0.008 & 0.007 & 131.30 \\
\hline $\mathrm{H} 2$ & $\mathrm{Y}=\mathrm{SO}+\mathrm{sex}+$ age + rank & 2733.22 & 10.56 & 0.005 & 0.005 & 195.88 \\
\hline H4 & $Y=S O+$ sex + age + rank + DC & 2734.61 & 11.94 & 0.003 & 0.002 & 391.11 \\
\hline $\mathrm{H} 7 \mathrm{~b}$ & $Y=S O+$ sex + age + rank $+D C+D C^{*}$ sex & 2735.81 & 13.14 & 0.001 & 0.001 & 713.37 \\
\hline $\mathrm{H} 7 \mathrm{a}$ & $\begin{array}{l}\mathrm{Y}=\mathrm{SO}+\mathrm{sex}+\text { age }+ \text { rank + DC + } \\
\text { rank*sex }\end{array}$ & 2736.43 & 13.76 & 0.001 & 0.001 & 972.63 \\
\hline H6 & $\begin{array}{l}\mathrm{Y}=\mathrm{SO}+\mathrm{sex}+\text { age }+ \text { rank }+\mathrm{DC}+ \\
\text { rank*age }\end{array}$ & 2739.28 & 16.61 & 0.000 & 0.000 & 4035.96 \\
\hline
\end{tabular}

2 Random effect: Cage; $N=234$; SO: Sampling order; DC: Dominance certainty; 


\section{Table 6 (on next page)}

Model fitting for diarrhea 
1 Table 6: Model fitting for diarrhea

\begin{tabular}{|c|c|c|c|c|c|c|}
\hline & Model & $\mathrm{AICC}$ & $\triangle \mathrm{AICc}$ & $\begin{array}{l}\text { Model } \\
\text { Likelihood }\end{array}$ & $\begin{array}{l}\text { Model } \\
\text { Weight }\end{array}$ & $\begin{array}{l}\text { Evidence } \\
\text { Ratio }\end{array}$ \\
\hline $\mathrm{H} 4$ & $Y=$ sex + age + rank + DC & 394.55 & 0 & 1.00 & 0.257 & 1.00 \\
\hline H3 & $Y=$ sex + age $+D C$ & 394.65 & 0.10 & 0.95 & 0.245 & 1.05 \\
\hline $\mathrm{H} 7 \mathrm{~b}$ & $Y=$ sex + age + rank $+D C+D C *$ sex & 396.17 & 1.62 & 0.45 & 0.114 & 2.25 \\
\hline $\mathrm{H} 2$ & $\mathrm{Y}=$ sex + age + rank & 396.49 & 1.94 & 0.38 & 0.097 & 2.64 \\
\hline H5 & $Y=$ sex + age + rank $+D C+$ rank $* D C$ & 396.60 & 2.04 & 0.36 & 0.092 & 2.78 \\
\hline $\mathrm{H} 7 \mathrm{a}$ & $Y=$ sex + age + rank $+D C+$ rank*sex & 396.64 & 2.09 & 0.35 & 0.090 & 2.84 \\
\hline $\mathrm{HO}$ & $Y=$ & 397.25 & 2.70 & 0.26 & 0.067 & 3.86 \\
\hline H6 & $Y=$ sex + age + rank $+D C+$ rank*age & 400.08 & 5.52 & 0.06 & 0.016 & 15.81 \\
\hline $\mathrm{H} 1$ & $Y=$ sex + age & 400.09 & 5.54 & 0.06 & 0.016 & 15.92 \\
\hline H8 & $\begin{array}{l}Y=\operatorname{sex}+\text { age }+ \text { rank }+D C+\operatorname{rank}^{*} D C+ \\
r^{*} k^{*} \text { sex }+D C^{*} \text { sex }+ \text { sex*rank*DC }\end{array}$ & 402.43 & 7.88 & 0.02 & 0.005 & 51.31 \\
\hline
\end{tabular}

2 Random effect: Cage; $\mathrm{N}=252$; Offset variable: days in cage; DC: Dominance certainty 


\section{Table 7 (on next page)}

Model coefficients from the set of candidate models for diarrhea bouts

${ }^{1} \mathrm{DC}$ : Dominance certainty. ${ }^{2}$ Males were referent category. ${ }^{3}$ Adults (6-12 yr) were the referent category. ${ }^{*} p<0.05 ;{ }^{+} p<0.1$ 
1 Table 7: Model coefficients from the set of candidate models for diarrhea bouts

\begin{tabular}{|c|c|c|c|c|c|c|}
\hline & $\begin{array}{c}(\mathrm{H} 4) \text { coeff } \\
(\mathrm{SE})\end{array}$ & $\begin{array}{c}\text { (H3) coeff } \\
(\mathrm{SE})\end{array}$ & $\begin{array}{c}\text { (H7b) coeff } \\
\text { (SE) }\end{array}$ & $\begin{array}{c}(\mathrm{H} 2) \text { coeff } \\
(\mathrm{SE})\end{array}$ & $\begin{array}{c}\text { (H5) coeff } \\
\text { (SE) }\end{array}$ & $\begin{array}{c}\text { (H7a) coeff } \\
\text { (SE) }\end{array}$ \\
\hline dAICc & 0 & 0.10 & 1.62 & 1.94 & 2.04 & 2.09 \\
\hline Intercept & $0.16(2.78)$ & $1.16(2.73)$ & $-1.30(3.39)$ & $-5.22(0.50)$ & $2.19(6.39)$ & $-0.01(2.84)$ \\
\hline Rank & $-0.96(0.64)$ & -- & $-1.14(0.69)^{+}$ & $1.42(0.60)$ & $-4.28(9.37)^{*}$ & $-1.09(0.80)^{+}$ \\
\hline$D C^{1}$ & $-7.00(3.54)^{*}$ & $-8.90(3.36)^{*}$ & $-5.10(4.34)$ & -- & $-9.46(7.81)$ & $-6.71(3.68)^{+}$ \\
\hline Sex ${ }^{2}$ & $-0.31(0.35)$ & $-0.27(0.35)$ & $3.60(5.31)$ & $-0.27(0.35)$ & $-0.29(0.35)$ & $-0.47(0.66)$ \\
\hline Rank $\times$ DC & -- & -- & -- & -- & $3.96(11.2)$ & -- \\
\hline Rank $\times$ Sex $^{2}$ & -- & -- & -- & -- & -- & $0.36(1.25)$ \\
\hline $\mathrm{DC} \times \mathrm{Sex}^{2}$ & -- & -- & $-4.85(6.60)$ & -- & -- & -- \\
\hline Rank $\times$ DC $\times$ Sex $^{2}$ & -- & -- & -- & -- & -- & -- \\
\hline $\mathrm{Age}^{3}-3 \mathrm{yr}$ & $-1.09(0.54)^{*}$ & $-0.90(0.53)^{+}$ & $-1.09(0.55)^{*}$ & $-1.13(0.55)^{*}$ & $-1.11(0.55)^{*}$ & $-1.09(0.55)^{*}$ \\
\hline Age - 4-5 yr & $0.067(0.36)$ & $0.20(0.35)$ & $0.09(0.36)$ & $-0.05(0.36)$ & $0.07(0.36)$ & $0.08(0.36)$ \\
\hline Age-13+yr & $0.65(0.42)$ & $0.62(0.42)$ & $0.69(0.43)$ & $0.60(0.43)$ & $0.63(0.43)$ & $0.64(0.42)$ \\
\hline
\end{tabular}

$2 \quad{ }^{1} \mathrm{DC}$ : Dominance certainty. ${ }^{2}$ Males were referent category. ${ }^{3} \mathrm{Adults}(6-12 \mathrm{yr})$ were the referent category.

$3 \quad * p<0.05 ;{ }^{+} p<0.1$

4

5 